\title{
Embryonic stem cell and induced pluripotent stem cell: an epigenetic perspective
}

\author{
Gaoyang Liang ${ }^{1,2,3}$, Yi Zhang ${ }^{1,2,3,4,5}$ \\ ${ }^{1}$ Howard Hughes Medical Institute, Harvard Medical School, WAB-149G, 200 Longwood Avenue, Boston, MA 02115, USA; ${ }^{2}$ Pro- \\ gram in Cellular and Molecular Medicine, Boston Children's Hospital, Harvard Medical School, WAB-149G, 200 Longwood Ave- \\ nue, Boston, MA 02115, USA; ${ }^{3}$ Department of Genetics, Harvard Medical School, WAB-149G, 200 Longwood Avenue, Boston, MA \\ 02115, USA; ${ }^{4}$ Department of Pediatrics, Harvard Medical School, WAB-149G, 200 Longwood Avenue, Boston, MA 02115, USA; \\ ${ }^{5}$ Harvard Stem Cell Institute, Harvard Medical School, WAB-149G, 200 Longwood Avenue, Boston, MA 02115, USA
}

Pluripotent stem cells, like embryonic stem cells (ESCs), have specialized epigenetic landscapes, which are important for pluripotency maintenance. Transcription factor-mediated generation of induced pluripotent stem cells (iPSCs) requires global change of somatic cell epigenetic status into an ESC-like state. Accumulating evidence indicates that epigenetic mechanisms not only play important roles in the iPSC generation process, but also affect the properties of reprogrammed iPSCs. Understanding the roles of various epigenetic factors in iPSC generation contributes to our knowledge of the reprogramming mechanisms.

Keywords: epigenetics; pluripotency; iPS cell; reprogramming

Cell Research (2013) 23:49-69. doi:10.1038/cr.2012.175; published online 18 December 2012

\section{Introduction}

Embryonic stem cells (ESCs) derived from the inner cell mass of a blastocyst are pluripotent stem cells with unique properties of pluripotency and self-renewal. They can divide indefinitely in vitro, while maintaining the capacity to generate all the cell types of an adult organism. The unique identity of ESCs is governed by a network of transcriptional factors along with epigenetic factors $[1,2]$. The epigenetic status of ESCs features an open chromatin structure with characteristic histone and DNA modification profiles.

Somatic cells can acquire the ESC properties through nuclear reprogramming. Three major approaches, including somatic cell nuclear transfer (SCNT), cell fusion and introduction of defined transcription factors, have been established to reprogram somatic cells to pluripotency [3, 4]. The latter approach was first reported by Yamanaka and colleague [5], who demonstrated that the expression of combined transcription factors, Oct4, Sox2, Klf4 and c-Myc is capable of reprogramming somatic cells into

Correspondence: Yi Zhang

E-mail: yzhang@genetics.med.harvard.edu
ESC-like cells, termed induced pluripotent stem cells (iPSCs). Since its initial report, this technology has attracted great attention and motivated many investigations because of its technical simplicity and tremendous application potentials in regenerative medicine.

iPSCs have been shown to be highly similar to ESCs, in terms of transcription program, chromatin modification profiles [5-12] and global chromatin configuration [6, $13,14]$. Functionally, at least some of the iPSCs have the developmental potential equivalent to ESCs, as entirely iPSC-derived animals ("all-iPSC" mice) can be generated through tetraploid complementation [15-17]. Despite that the approach for iPSC generation is well established $[3,18]$, questions remain as to how reprogramming factors drive somatic cells into iPSCs and why the reprogramming process is extremely inefficient in terms of time and the conversion rate from starting cells to iPSCs.

Since any cell fate change is largely an epigenetic process, it is conceivable that potential epigenetic barriers may restrict the transition from somatic cells to iPSCs. Overcoming these epigenetic barriers might be a prerequirement for successful generation of iPSCs. Consistent with this notion, many epigenetic factors (Table 1) and chemical modulators of epigenetic modifications (Table 2) are capable of affecting reprogramming efficiency. In this 
Table 1 Epigenetic factors involved in iPSC generation

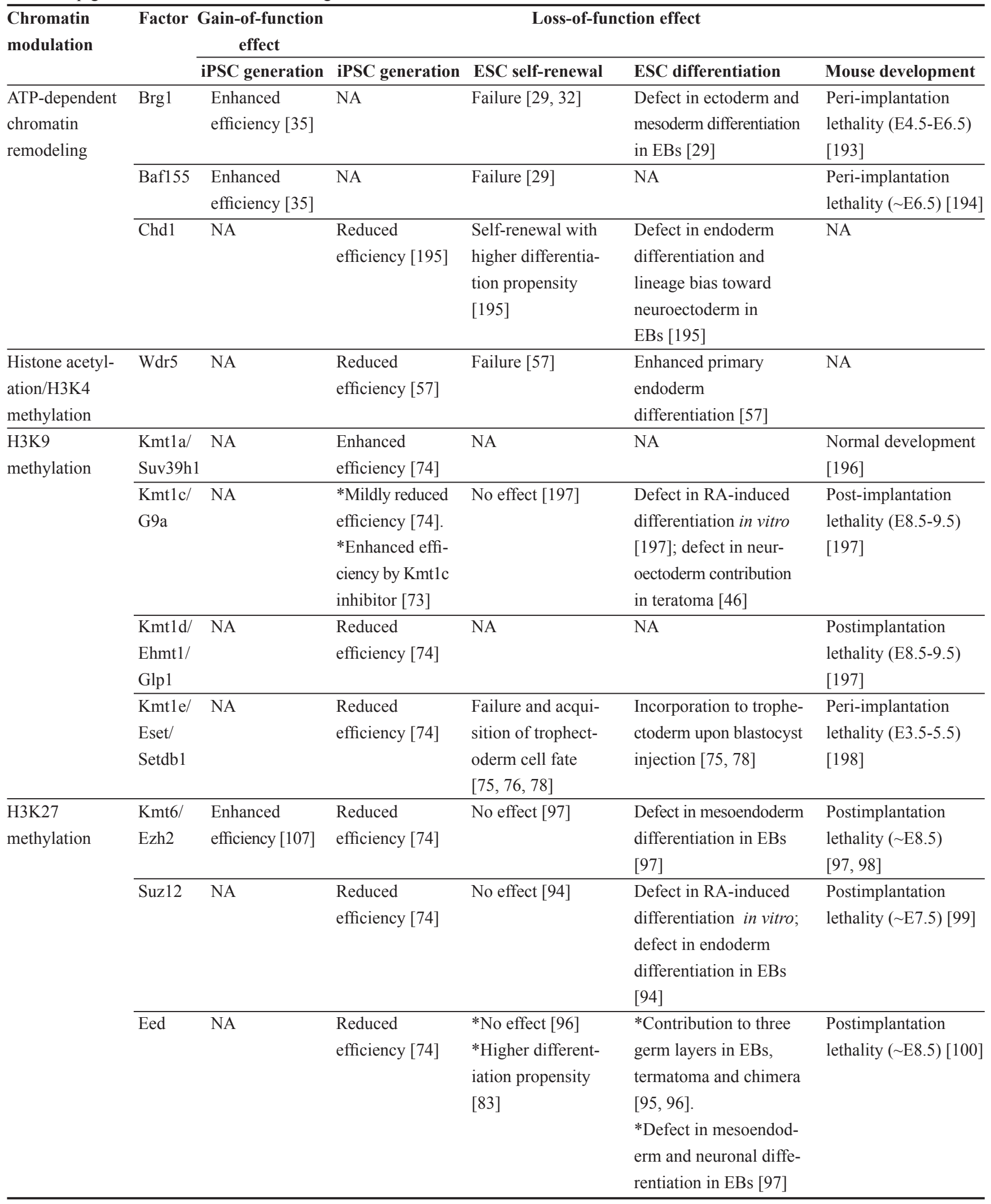


Table 1 Epigenetic factors involved in iPSC generation (continued)

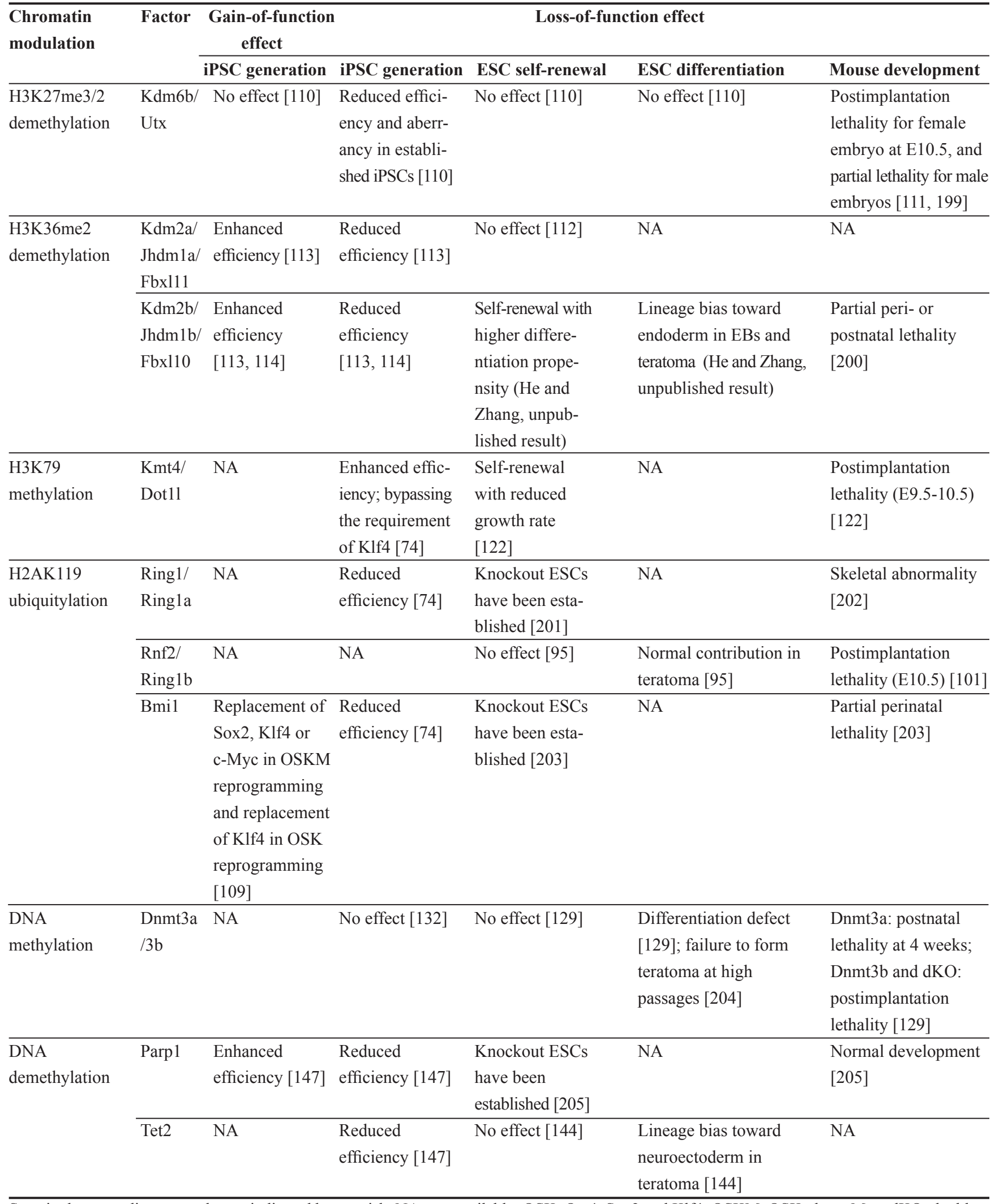

Seemingly contradictory results are indicated by asterisk. NA, not available; OSK, Oct4, Sox2 and Klf4; OSKM, OSK plus c-Myc; dKO, double knockout; EBs, embryoid bodies; RA, retinoic acid. 
review, we first discuss the roles of epigenetic regulations in ESC maintenance and iPSC generation. We then discuss our current understanding of the mechanisms underlying iPSC generation with a focus on epigenetic reprogramming.

\section{Epigenetic regulations in ESCs and reprogram- ming to iPSCs}

The pluripotent state of ESCs is enforced by epigenetic factors closely linked to the pluripotency transcription factor network $[1,2]$. Resetting the epigenetic state of somatic cells to that of ESCs is one of the ultimate tasks for the reprogramming factors in iPSC generation. The epigenetic factors involved in maintaining the pluripotency of ESCs must be activated through the reprogramming process. Furthermore, epigenetic modulating strategies must be used to overcome the inherent somatic epigenetic state. Therefore, some epigenetic factors may function specifically to erase somatic epigenetic statuses. In this section, we discuss the detailed roles of epigenetic modulations in iPSC generation by juxtaposing the functions of these modulations in maintaining ESC identity and in establishing iPSC pluripotency.

\section{Global chromatin reorganization in iPSC generation}

Compared with differentiated cells, ESCs display distinctive chromatin features related to its unique properties. The chromatin in ESCs is in an "open" state, with more accessible chromatin domains and less heterochromatin foci. In contrast, highly condensed heterochromatin foci are prevalent in lineage-committed somatic cells [19-22]. Consistent with this, genome-wide distribution of repressive histone modifications is less prevailing in ESCs, compared with differentiated cells [23, 24]; and active histone modifications are more abundant in ESCs $[19,20,25,26]$. Additionally, the hyperdynamics of nu- clear proteins [19] and hyperactivity of global transcription in ESCs [20] also indicate that the ESC chromatin is in a permissive state.

During iPSC generation, the somatic cell chromatin needs to be reorganized to an ESC-like state with loosely organized heterochromatin and abundant euchromatin modifications $[13,14]$. It appears that the chromatin reorganization events take place in a coordinated and sequential manner. Rearrangement of the heterochromatin, characterized by the presence of histone $\mathrm{H} 3$ lysine 9 trimethylation (H3K9me3) and HP1, precedes the activation of Nanog, while enrichment of euchromatin marks occurs concurrently with Nanog activation [14]. Consistently, heterochromatin is rearranged and becomes dispersed when partially reprogrammed cells are converted to iPSCs by dual inhibition of MEK and GSK3 [13]. Thus, chromatin reorganization from the somatic state to an ESC-like one seems to be required for the activation of pluripotency circuitry. However, such a drastic chromatin rearrangement appears to have a substantial latency in the reprogramming process. Detailed characterization of these changes at the molecular level is difficult due to the low percentage of somatic cells that can be successfully converted to iPSCs.

To overcome the problem associated with cell population heterogeneity during the reprogramming process, one study focused on examining the histone modification changes in the first several cell cycles after the induction of the reprogramming factors. In this initial stage of reprogramming, a global change in $\mathrm{H} 3 \mathrm{~K} 4 \mathrm{me} 2$ distribution is observed [27]. De novo acquisition or further enrichment of this modification occurs at large numbers of gene loci, including those encoding pluripotency factors and their targets. Although $\mathrm{H} 3 \mathrm{~K} 4 \mathrm{me} 2$ is classified as an active chromatin mark, change in local H3K4me2 level does not result in gene expression change [27]. Altered expression patterns can mainly be detected at gene loci

Table 2 Epigenetic-modulating small molecules that affect iPSC generation

\begin{tabular}{lll}
\hline Chemical & Function & Effect on iPSC generation \\
\hline 5-Azacytidine & DNA methylation inhibitor & Conversion of partially reprogrammed cells to iPSCs [7] \\
BIX-01294 & H3K9 methyltransferase & Enhanced efficiency [73]; facilitating generation of iPSCs with Oct4/K1f4 from \\
& Kmt1c/G9a inhibitor & MEFs [206] \\
Butyrate & HDAC inhibitor & Enhanced efficiency [51, 52]; reduced frequency of partially reprogrammed cells [52] \\
EPZ004777 & H3K79 methyltransferase & Enhanced efficiency; generation of iPSCs with Oct4 and Sox2 from fibroblasts [74] \\
& Kmt4/Dot1l inhibitor & \\
Valproic acid & HDAC inhibitor & Enhanced efficiency [49, 50]; generation of iPSCs with Oct4 and Sox2 from human \\
& & $\begin{array}{l}\text { fibroblasts [50]. } \\
\text { Vitamin C }\end{array}$ \\
& Regeneration of cofactor & Enhanced efficiency individually and synergistically with Kdm2b [113, 121]; improve- \\
& Fent of iPSC quality by preventing aberrant silencing on the Dlk1-Dio3 locus [154] \\
\hline
\end{tabular}


marked with $\mathrm{H} 3 \mathrm{~K} 4 \mathrm{me} 3$ [27], indicating that somatic chromatin status may restrict the activity of reprogramming factors. Consistent with this notion, the distribution of the H3K27me3 repressive mark is largely unchanged [27], implicating that drastic transition of epigenetic landscapes has yet to occur after these initial changes.

\section{ATP-dependent chromatin remodeling}

Global or local chromatin structure is regulated in part by ATP-dependent chromatin-remodeling factors. These factors are capable of regulating DNA accessibility by depositing, replacing or evicting nucleosomes [28]. Multiple chromatin-remodeling factors belonging to different classes have been shown to regulate the ESC identity. The SWI/SNF class ESC-specific BAF (esBAF) complex is essential for ESC maintenance. ESCs lacking the esBAF components are deficient in self-renewal and display an abnormal differentiation program [29-32]. The esBAF catalytic subunit Brg1 shares a substantial portion of targets with core pluripotency factors [32, 33], and contributes to pluripotency with dual functions in transcription regulation [34]: Brg1 facilitates the activation of its targets involved in the LIF-STAT3 pathway, an essential pathway for ESC self-renewal, by antagonizing Polycomb repressive complex (PRC) 2-mediated repression; meanwhile, it reinforces the repression on the differentiation-related Hox gene loci [34]. By tracing nuclear fractions that can transiently activate the Oct4 locus, esBAF components were found to be capable of increasing reprogramming efficiency [35], consistent with their role in shaping the chromatin state in ESCs. In the presence of esBAF components, euchromatin features at certain pluripotency gene loci are more prominent at the intermediate stage of reprogramming, and the accessibility of these loci to the reprogramming factors is enhanced [35].

The CHD class remodeling factor, Chd1, preferentially binds to euchromatin and colocalizes with RNA polymerase II (Pol II) [36]. Chd1 helps maintain the open chromatin in ESCs, as depletion of Chd1 leads to accumulation of heterochromatin and interferes with proper differentiation. Consistently, Chd 1 deficiency reduces reprogramming efficiency [36], indicating that establishing the ESC chromatin state is crucial for acquiring pluripotency.

Two other CHD class remodeling factors, Chd3 and Chd4 (also known as Mi2- $\alpha$ and Mi2- $\beta$ ) reside in the NuRD complex, which also harbors histone deacetylases HDAC1 and HDAC2. In ESCs, NuRD functionally converges with other repressive machinery, including PRC2 and $\mathrm{H} 3 \mathrm{~K} 4 \mathrm{me} 2$-specific demethylase Kdm1a (also called Lsd1 or Aof2), while eliciting effects opposite to Brg1
[37-39]. ESCs lacking Mbd3, an essential component of $\mathrm{NuRD}$, exhibit elevated expression of certain pluripotency genes. Such an expression change is associated with LIF-independent self-renewal capacity and deficiency in lineage commitment upon differentiation [40, 41]. Moreover, NuRD has been shown to contribute to the autorepression of a set of pluripotency genes, whose expression are subjected to negative autoregulatory feedback control in serum-cultured ESCs [41, 42]. In particular, NuRD is recruited by the transcription factor Zfp281 and mediates Nanog autorepression [42]. The repressive effect of Zfp281 impedes Nanog activation during iPSC generation, and depletion of Zfp281 facilitates the conversion of partially reprogrammed cells, or "pre-iPSCs", to iPSCs [42]. It will be interesting to determine whether depletion of NuRD results in similar effects on iPSC generation.

The INO family Tip60-p400 complex, which possesses both chromatin remodeling and histone acetyltransferase (HAT) activities, is also essential for ESC maintenance. ESCs lacking Tip60-p400 subunits fail to self-renew or differentiate efficiently [43]. Tip60-p400 potentially regulates genes bound by Nanog and marked by $\mathrm{H} 3 \mathrm{~K} 4 \mathrm{me} 3$ through depositing histone $\mathrm{H} 4$ acetylation, and thereby contributes to the ESC identity [43]. Lastly, a study on the ISWI family remodeling complex Nurf revealed that, depletion of its essential component, Bptf, in ESCs leads to deficiency in differentiation into all three germ layers, albeit having minimal effect on ESC selfrenewal [44]. It is currently unknown whether Tip60p400 or Nurf plays a role in iPSC generation.

\section{Histone acetylation}

Histone-modifying enzymes play important roles in regulating ESC identity and the iPSC generation process. Histone modifications are thought to function by either directly affecting higher-order chromatin configurations or mediating chromatin-related processes through recruiting specific binding proteins [45]. Histone acetylation can potentially open up chromatin by neutralizing the positive charge of histone lysine residues. Consistent with this function, histone acetylation is highly enriched in ESCs compared with differentiated cells [19, 20, 25, 26], indicating that it contributes to the open chromatin state in ESCs. Consistently, treatments of HDAC inhibitors have been shown to enhance nuclear dynamics, reduce differentiation propensity [46] and support the selfrenewal program in ESCs [47]. In addition, in cell fusion-mediated reprogramming, low levels of histone H3 $\mathrm{K} 9$ acetylation (H3K9ac) in ESCs correlate with reduced efficiency in reprogramming the nuclei from fibroblasts, and HDAC inhibitors can improve the reprogramming efficiency [48]. 
In support of the role of histone acetylation in reprograming, HDAC inhibitors, including valproic acid (VPA) and butyrate, significantly improve the efficiency of iPSC generation [49-52]. Butyrate also promotes the reprogramming fidelity by reducing the frequency of partially reprogrammed cells [52]. Treatments of the reprogramming cells with HDAC inhibitors lead to enhanced expression of ESC-enriched genes before the establishment of pluripotency [49, 51, 52]. Furthermore, the role of VPA in reprogramming can be at least partly attributed to its ability to induce HDAC2 degradation [53]. It has been reported that VPA treatment or HDAC2 depletion allows reprogramming by the microRNA cluster miR302/367 without introducing any other factors [53]. Finally, HDAC inhibitors have also been applied to rectify aberrantly silenced loci and eliminate the somatic cell memory in established iPSC lines [54, 55].

Despite the prevailing evidence for the association between histone acetylation and pluripotency, it is surprising that few reports have identified the function of individual HATs or HDACs in regulating pluripotency. A recent study showed that, Kat8 (also called Mof or Myst1), a HAT catalyzing H4K16ac, is important for ESC identity [25]. Kat8 deletion abolishes the self-renewal capacity and pluripotency of ESCs. Mechanistically, Kat8 has been found to regulate the ESC transcription network by functioning upstream to activate Nanog [25]. Interestingly, Wdr5, a shared component of the Kat8-containing complex and the MLL complex catalyzing H3K4 methylation [56], displays a phenotype similar to that of Kat8 when depleted in ESCs [57]. Given that Dpy30, another MLL complex component regulating H3K4 methylation, is dispensable for ESC self-renewal [58], it seems likely that the Kat8-containing complex mediates the Wdr5 function. In support of this notion, the recruitment of $\mathrm{Wdr} 5$ to its target loci, including key pluripotency genes, depends on Kat8 [25]. The fact that the binding of Wdr5 to these loci results in an enrichment of $\mathrm{H} 3 \mathrm{~K} 4 \mathrm{me} 3$ indicates a hierarchical relationship between these histone modifications [25]. Wdr5 has been shown to be required for efficient generation of iPSCs [57]. It will be interesting to investigate the potential effect of Kat8 on iPSC generation. Kat8 may enhance the reprogramming efficiency by directly activating Nanog and promote the conversion of pre-iPSCs to iPSCs.

\section{Histone methylation}

Histone methylation is closely linked to transcription. Methylations on different residues and sometimes to different degrees (i.e., tri-, di- or mono-) represent differential transcriptional statuses. Generally, transcription activation is associated with $\mathrm{H} 3 \mathrm{~K} 4 \mathrm{me} 3 / 2$ at promoter, and $\mathrm{H} 3 \mathrm{~K} 36 \mathrm{me} 3 / 2$ and $\mathrm{H} 3 \mathrm{~K} 79 \mathrm{me} 3 / 2$ across the transcribed region, while transcription silencing correlates with $\mathrm{H} 3 \mathrm{~K} 27 \mathrm{me} 3 / 2$ at promoter and $\mathrm{H} 3 \mathrm{~K} 9$ and $\mathrm{H} 4 \mathrm{~K} 20$ methylation in heterochromatic regions [59-61]. However, accumulating evidence has challenged this generalized view, arguing for a more context-dependent role of histone methylation in transcription regulation [62].

H3K4 methylation In lower eukaryotes, H3K4 methylation enriched in the promoter highly correlates with transcription activation [59]. However, in mammalian cells, promoter $\mathrm{H} 3 \mathrm{~K} 4 \mathrm{me} 3$ does not seem to strictly associate with gene expression. Instead, the majority of promoters are marked by $\mathrm{H} 3 \mathrm{~K} 4 \mathrm{me} 3$, regardless of the gene expression status $[63,64]$. Although the presence of both $\mathrm{H} 3 \mathrm{~K} 4 \mathrm{me} 3$ and Pol II at promoter is an indication of transcription allowance [63, 64], productive transcription relies on the rate-limiting step of RNA Pol II releasing from the promoter $[63,65,66]$. The inactive state of some H3K4me3-marked genes can also be attributed to the coexistence of repressive modifications, such as H3K27me3 (see below). These repressive modifications appear to play a dominant role in determining the transcription status.

In ESCs, the overall prevalence of $\mathrm{H} 3 \mathrm{~K} 4 \mathrm{me} 3$ at promoter is similar to that in the differentiated cells. However, cell type-specific $\mathrm{H} 3 \mathrm{~K} 4 \mathrm{me} 3$ pattern can be detected and is frequently correlated to cell type-specific gene expression [63, 67]. Enzymes depositing or removing H3K4 methylation have been shown to play important roles in ESCs. Dpy30, a component of the MLL histone methyltransferase (HMT) complex, is required for ESCs to commit to the neural lineage [58], indicating that $\mathrm{H} 3 \mathrm{~K} 4 \mathrm{me} 3$ deposited by MLL is crucial for maintaining differentiation potential in ESCs. Deficiency in $\mathrm{Kdm} 1 \mathrm{a}$, an $\mathrm{H} 3 \mathrm{~K} 4 \mathrm{me} 2 / 1$-specific demethylase, results in spontaneous differentiation of human ESCs [68]. Kdm1a targets developmental genes co-occupied by $\mathrm{H} 3 \mathrm{~K} 4 \mathrm{me} 3 / 2$ and $\mathrm{H} 3 \mathrm{~K} 27 \mathrm{me} 3$ and contributes to their repression by balancing the H3K4 methylation level [68]. Another demethylase, $\mathrm{Kdm} 5 \mathrm{~b}$ (also called Plu1), which is specific for $\mathrm{H} 3 \mathrm{~K} 4 \mathrm{me} 3 / 2$, is essential for ESC self-renewal [69]. $\mathrm{Kdm} 5 \mathrm{~b}$ contributes to the activation of self-renewalrelated genes, which preferentially function in nucleotide metabolism, cell division and chromatin regulation. Kd$\mathrm{m} 5 \mathrm{~b}$ is located to the transcribed region of these genes, repressing intragenic cryptic transcription and sustaining efficient transcription elongation [69]. The potential roles of these enzymes in iPSC generation remain to be tested.

H3K9 methylation H3K9 methylation is associated with transcription silencing and heterochromatin formation. 
Genome-wide localization studies have shown that the genomic domains marked with $\mathrm{H} 3 \mathrm{~K} 9 \mathrm{me} 3$ are substantially expanded in differentiated cells compared with ESCs [23], and long-range silenced genomic regions marked by $\mathrm{H} 3 \mathrm{~K} 9 \mathrm{me} 2$ are also increased upon differentiation [24]. It has been shown that, upon exiting the pluripotent state, H3K9-specific HMT Kmt1c (also called G9a) contributes to the silencing of the Oct4 locus by forming heterochromatin structure and recruiting the de novo DNA methylation machinery [70]. While Kmt1c plays a role in differentiation-induced silencing, $\mathrm{H} 3 \mathrm{~K} 9 \mathrm{me} 3 / 2$ specific histone demethylases (HDMs), Kdm3a and Kd$\mathrm{m} 4 \mathrm{c}$ (also called Jhdm2a/Jmjd1a and Jhdm3c/Jmjd2c, respectively) are essential for maintaining the ESC identity [71]. Knocking down either $\mathrm{Kdm} 3 \mathrm{a}$ or $\mathrm{Kdm} 4 \mathrm{c}$ in ESCs blocks ESC self-renewal and leads to differentiation [71]. In ESCs, Kdm3a regulates a distinct set of pluripotency genes, including Tcl1, Tcfcp $2 l 1$ and Zfp57, while Kdm4c contributes to the activation of Nanog [71].

Consistent with the roles of these enzymes in regulating pluripotency, inhibition of Kmt1c and/or overexpression of Kdm3a increases the efficiency of SCNT and cell fusion-based reprogramming [70, 72]. In transcription factors-induced reprogramming, inconsistent results are reported for the role of Kmtlc. Treatment of Kmt1c inhibitor has been shown to increase reprogramming efficiency [73]; however, another study showed that depletion of Kmt1c by small hairpin RNA (shRNA) does not increase reprogramming efficiency [74]. More studies are needed to clarify the role of $\mathrm{Kmt} 1 \mathrm{c}$ and to investigate the potential role of $\mathrm{H} 3 \mathrm{~K} 9 \mathrm{me} 3 / 2$-specific demethylases in iPSC generation.

In ESCs, H3K9 methylation also functions in repressing trophectoderm-specific genes. ESCs lacking Kmtle (also called Setdb1 or Eset), an H3K9-specific HMT, fail to self-renew while acquiring trophectoderm properties [75-78]. Consistent with its role in ESCs, depletion of Kmtle reduces the reprogramming efficiency in iPSCs generation [74]. In addition to Kmtle, other H3K9specific HMTs have also been shown to affect iPSC generation. Depletion of Kmt1d (also called Ehmt1 or Glp1) reduces iPSC generation efficiency, while depletion of Kmtla (also called Suv39h1) enhances iPSC generation, manifesting the complexity of the roles of H3K9 methylation in shaping pluripotency. How these HMTs function in iPSC generation and/or ESC maintenance requires further studies.

H3K27 methylation $\mathrm{H} 3 \mathrm{~K} 27 \mathrm{me} 3$ is a repressive modification placed by PRC2. Much attention has been drawn to its role in ESCs for its involvement in the "bivalent" domain, which is coined by the coexistence of the repres- sive mark $\mathrm{H} 3 \mathrm{~K} 27 \mathrm{me} 3$ and the active mark $\mathrm{H} 3 \mathrm{~K} 4 \mathrm{me} 3$ [79]. Genes that harbor the bivalent domain are transcriptionally silenced in ESCs, suggesting a potentially dominant role of $\mathrm{H} 3 \mathrm{~K} 27 \mathrm{me} 3$. In ESCs, genes with bivalent domain include a substantial number of differentiationrelated genes targeted by the core pluripotency factors $[67$, 79-82]. Upon differentiation, these bivalent domains are often resolved, leaving either $\mathrm{H} 3 \mathrm{~K} 27 \mathrm{me} 3$ or $\mathrm{H} 3 \mathrm{~K} 4 \mathrm{me} 3$, indicative of the expression status $[67,79,80]$. It is believed that the bivalent domain keeps the differentiationactivated promoters in a "poised" state, allowing rapid response to differentiation cues. Consistently, bivalent differentiation-related genes are bound by PRC2 components in ESCs [83-85]. Recruitment of PRC2 to these targets are directed by the PRC2-associated protein Jarid2 or Mtf2 [86-91]. In addition, part of the targets repressed by PRC2 are further occupied by PRC1, which establishes another repressive mark, histone H2A K119 ubiquitylation (H2AK119ub) [84, 88, 92, 93]. The recruitment of PRC1 to these loci is thought to fortify the gene repression during differentiation [93].

Despite its intriguing genomic distribution, the functional significance of $\mathrm{H} 3 \mathrm{~K} 27 \mathrm{me} 3$ in ESCs is controversial. Several lines of evidence indicate that H3K27me3 may play a more important role in differentiation rather than in ESC maintenance, and the deposition of H3K27me3 may simply mark the genes that need to be activated upon differentiation. First, ESCs lacking PRC2 activity retain the self-renewal capacity, although the expression of PRC2 target genes is slightly derepressed in these ESCs $[83,94-97]$. The fact that PRC2-deficient ESCs only display deficiency upon ESC differentiation [94-97] is consistent with the postimplantation lethality phenotype of PRC2-deficient animals (Table 1) [98101]. Second, the bivalent domain is not limited to ESCs or progenitor cells, as it is also found in terminally differentiated cells $[67,81,82,102,103]$, suggesting that the bivalent structure itself may not exclusively stand for differentiation potential. Third, a recent study of the ground state ESCs, a primitive pluripotent state enforced by MEK and GSK3 inhibitors (2i), showed that, compared to serum-cultured ESCs, H3K27me3 is dramatically reduced in $2 \mathrm{i}$-cultured ESCs. This results in the loss of bivalency for two-thirds of the bivalent genes [104]. However, the genes losing bivalency in $2 \mathrm{i}$ culture are still effectively silenced in this condition [104], suggesting that other mechanisms must contribute to the repression of these loci. Along this line, a recent study showed that PRC2 is preferentially recruited to chromatin with highdensity nucleosomes [105], indicating that a non-permissive state of chromatin has already been established, at least, in part, before $\mathrm{H} 3 \mathrm{~K} 27 \mathrm{me} 3$ is deposited. Therefore, 
it appears that the repression state of $\mathrm{H} 3 \mathrm{~K} 27$ me3-marked genes in ESCs is not only enforced by PRC2, but that other functionally important repressive mechanisms may also be involved. Consistent with this notion, depletion of both PRC2 and PRC1 in ESCs leads to a much more severe differentiation phenotype compared with the cells lacking either one of them [95]. Collectively, H3K27me3 contributes to the repression of developmental genes in ESCs, but its detailed role in regulating ESC pluripotency requires further investigation.

Although controversy remains for the function of H3K27me3 and PRC2 in ESCs, PRC2 components have been shown to be critical for somatic cell reprogramming. Cell fusion-based reprogramming studies demonstrated that ESCs lacking PRC2 component Suz12 or Eed have reduced capacity to reprogram somatic cell nuclei [106]. Consistently, in iPSC generation, depleting each of the PRC2 complex core components, Kmt6 (also called Ezh2), Suz12 or Eed, dramatically reduces reprogramming efficiency [74, 107, 108], and overexpression of Kmt6 increases reprogramming efficiency [107]. Other proteins specifically associated with PRC2 in ESCs, including Jarid2, Mtf2 and Esprc2p48, also promote iPSC generation synergistically [108]. Furthermore, Kmt6 has been shown to be activated by a hierarchy of pluripotency factors in the late phase of iPSC generation and its activation in part contributes to pluripotency establishment [107]. In addition, components of PRC1, which is functionally relevant to PRC2, are also important for iPSC generation. Ring1 (also called Ring1a) and Bmil are required for efficient reprogramming [74, 109], and ectopic expression of Bmil is sufficient to mediate iPSC generation from fibroblasts when combined with Oct4 [109].

Interestingly, removal of $\mathrm{H} 3 \mathrm{~K} 27$ methylation is also involved in reprogramming. Utx, an $\mathrm{H} 3 \mathrm{~K} 27 \mathrm{me} 3 / 2$ specific demethylase, is required for efficient reprogramming in both cell fusion-mediated and transcription factors-induced reprogramming [110]. iPSCs derived in the absence of Utx bear aberrant H3K27me3 and H3K4me3 profiles. Mechanistically, Utx specifically regulates a set of pluripotency genes, including Sall1, Sall4 and Utf1, whose activation is important for establishing pluripotency [110]. Although Utx is dispensable for ESC derivation and maintenance, Utx-deficient ESCs are crippled in differentiation $[110,111]$. Overall, it seems that the dynamic regulation of $\mathrm{H} 3 \mathrm{~K} 27$ methylation plays a more important role in the transition of cell identities, including differentiation and reprogramming, than in the maintenance of ESC status.

H3K36 methylation H3K36 methylation, especially
$\mathrm{H} 3 \mathrm{~K} 36 \mathrm{me} 3 / 2$, is involved in transcription elongation, marking actively transcribed loci in the gene body. Recent study has suggested that depletion of H3K36me2, along with the deposition $\mathrm{H} 3 \mathrm{~K} 4 \mathrm{me} 3$, at $\mathrm{CpG}$-rich promoter helps establish a platform for the assembly of gene regulatory machinery [112]. Removal of H3K36me2 can be directed by the JmjC domain-containing demethylases, Kdm2a and Kdm2b (also called Jhdm1a/Fbx111 and Jhdm $1 \mathrm{~b} / \mathrm{Fbxl10}$, respectively). ESCs lacking Kdm2a appear to be normal in self-renewal [71, 112], while $\mathrm{Kdm} 2 \mathrm{~b}$-deficient ESCs maintain the expression of pluripotency genes, but display a skewed lineage commitment upon differentiation (He and Zhang, unpublished data).

We and others have found that $\mathrm{Kdm} 2 \mathrm{~b}$ is capable of enhancing iPSC generation [113, 114]. Kdm2b functions early in reprogramming by promoting the activation of epithelial genes [114]. It has been shown that activation of epithelial genes through mesenchymal-to-epithelial transition (MET) is an early event in reprogramming [115, 116]. Consistent with the role of H3K36 demethylation in reprogramming, the bulk $\mathrm{H} 3 \mathrm{~K} 36 \mathrm{me} 3 / 2$ level decreases during the iPSC generation process [113]. Interestingly, dynamic regulation of $\mathrm{H} 3 \mathrm{~K} 36$ methylation is not limited to the MET process during iPSC generation. Global H3K36me3 level has been shown to become more abundant when an epithelial cell line is induced to a mesenchymal state [117], indicating a general link between H3K36 methylation and mesenchymal-epithelial state. The role of $\mathrm{Kdm} 2 \mathrm{~b}$ in epithelial gene activation appears to be direct, as $\mathrm{Kdm} 2 \mathrm{~b}$ binds to and modulates the H3K$36 \mathrm{me} 2$ level of the activated epithelial gene loci during reprogramming [114]. Interestingly, Kdm2b-mediated enhancement of epithelial gene activation is followed by the elevated activation of pluripotency genes, such as Nanog. However, the activation of Nanog takes place outside the functioning time window of $\mathrm{Kdm} 2 \mathrm{~b}$ [114], suggesting a potential link between the sequential gene activation events in iPSC generation. In addition, inhibition of the epithelial gene activation largely abrogates the enhancing effect of Kdm2b in iPSC generation [114], indicating that activation of epithelial genes is a prerequisite for pluripotency establishment. How activation of epithelial genes facilitates the establishment of pluripotency remains to be determined.

In addition, vitamin $\mathrm{C}$ has been shown to promote iPSC generation synergistically with $\mathrm{Kdm} 2 \mathrm{~b}$ [113]. Such a synergy between vitamin $\mathrm{C}$ and $\mathrm{Kdm} 2 \mathrm{~b}$ can be explained by the capacity of vitamin $\mathrm{C}$ to convert the oxidative $\mathrm{Fe}$ (III) to the reduced $\mathrm{Fe}$ (II) [118]. Fe(II) is a cofactor required for dioxygenase-catalyzed oxidation reactions, including histone demethylation by JmjC domain-containing proteins such as $\operatorname{Kdm} 2 b[119,120]$. 
Since vitamin $\mathrm{C}$ also enhances iPSC generation by itself $[113,121]$, it would be interesting to test whether vitamin $\mathrm{C}$ contributes to reprogramming by potentiating other reprogramming-related enzymatic activities.

H3K79 methylation H3K79 methylation, catalyzed by $\mathrm{Kmt} 4$ (or Dot1L), is associated with active transcription and usually enriched in the gene body [61]. Kmt4-depleted ESCs appear to self-renew with pluripotency markers expressed but have a lower proliferation rate [122]. Kmt4 deletion in ESCs also leads to the loss of $\mathrm{H} 3 \mathrm{~K} 9 \mathrm{me} 2$ and $\mathrm{H} 4 \mathrm{~K} 20 \mathrm{me} 3$ at centromeres and telomeres, resulting in a less condensed chromatin state [122]. Kmt4 deficiency in mice causes embryonic lethality with multiple developmental abnormalities [122]. How this phenotype is reflected in differentiation potentials in vitro is not clear.

Through a knockdown screening for epigenetic factors affecting iPSC generation, Kmt4 was found to impede iPSC generation. Depletion of Kmt4 by shRNA or inhibition of Kmt4 enzymatic activity by a small molecule significantly enhances the efficiency of iPSC generation [74]. Inhibition of Kmt4 in the early stage is sufficient for its enhancing effect on iPSC generation. Consistent with the functioning time window, Kmt4 inhibition attenuates the expression of mesenchymal transcription factors, facilitating the acquisition of epithelial features through MET [74]. Downregulation of mesenchymal genes is accompanied by the reduced H3K 79 me2 level on these loci, consistent with the association of $\mathrm{H} 3 \mathrm{~K} 79 \mathrm{me} 2$ with active transcription. Interestingly, upregulation of pluripotency genes, such as Nanog and Lin28, is also detected upon $\mathrm{Kmt} 4$ inhibition, and such an upregulation depends on the enhanced MET, which is caused by Kmt4 inhibition [74]. These observations again indicate that gaining of epithelial properties is a prerequisite for the activation of key pluripotency genes during iPSC generation.

Studies from H3K36 and K79 methylations suggest that, these two modifications appear to constitute a barrier for acquisition of epithelial properties during iPSC generation. In the reprogramming process, $\mathrm{Kdm} 2 \mathrm{~b}$ and factors antagonizing the function of Kmt4 presumably facilitate the elimination of specific inherent somatic barriers rather than to establish or maintain the pluripotency circuitry.

\section{DNA methylation and its derivatives}

Roles of DNA modifications in ESC maintenance and reprogramming to iPSCs One of the best-characterized DNA modifications is the methylation of cytosine $(\mathrm{mC})$ at the 5 position. $\mathrm{mC}$ is catalyzed by the de novo DNA methyltransferases Dnmt3a and Dnmt3b and maintained by Dnmt1. Most of the DNA methylation occurs in the context of CpG dinucleotide [123]. Genome-wide mapping of DNA methylation suggests that, in general, $\mathrm{CpG}$ rich promoters tend to be hypomethylated and CpG-poor ones hypermethylated [124-126]. DNA methylation at promoter is indicative of a repressive chromatin environment and inversely correlated with $\mathrm{H} 3 \mathrm{~K} 4 \mathrm{me} 3[67,125$, 126]. In ESCs, hypomethylated $\mathrm{CpG}$-rich promoters are enriched in ubiquitously expressed house-keeping genes and genes highly regulated during development. These gene loci are marked by either $\mathrm{H} 3 \mathrm{~K} 4 \mathrm{me} 3$ alone or bivalent modifications. In contrast, hypermethylated CpG-poor promoters are preferentially associated with tissue-specific genes that are devoid of H3K4me3 [124, 126]. Particularly, promoters of pluripotency genes such as Nanog and Oct4, are hypomethylated in ESCs. These genes become hypermethylated through de novo DNA methylation upon differentiation $[7,125,127]$. DNA methylation is not required for ESC maintenance as deletion of any or all of the three DNMTs does not affect the self-renewal capacity of ESCs [128-130]. However, DNMT-deficient ESCs fail to execute lineage commitment upon differentiation signaling in vitro [131]. Studies in mouse models also showed that deletion of Dnmt1 or Dnmt3b leads to postimplantation lethality and mice lacking Dnmt3a exhibit early postnatal lethality [128, 129], supporting a critical role of DNA methylation in development. Nevertheless, somatic cells that lack Dnmt3a and Dnmt3b can be converted into iPSCs with comparable, if not better, reprogramming efficiency [132], suggesting that de novo DNA methylation is not important for transcription factors-directed establishment of pluripotency.

DNA methylation can be passively diluted by inhibition of DNMTs through cell cycle progression or actively removed by various potential mechanisms [133]. Among these mechanisms, Tet protein-mediated oxidation has been implicated in the functioning in ESCs. Tet proteins are dioxygenases capable of oxidizing $5 \mathrm{mC}$ to hydroxylmethylcytosine $(\mathrm{hmC})$, formylcytosine and carboxylcytosine [134-137]. Two of the Tet proteins, Tet1 and Tet2, are enriched in ESCs [135]. Genome-wide localization analysis revealed that, Tet1 and $\mathrm{hmC}$ are preferentially enriched at the $\mathrm{CpG}$-rich promoters, including those in bivalent gene loci [138-142]. It has been suggested that Tet 1 and hmC play dual functions in regulating gene expression: Tetl and $\mathrm{hmC}$ potentially support gene activation at pluripotency genes, while contributing to the silenced state of bivalent genes. Deficiency in Tet1, Tet2 or Tet $1 / 2$ in ESCs does not seem to affect ESC maintenance or pluripotency [140, 143, 144], but skewed differentiation can be detected when these ESCs are subjected to differentiation $[135,142-144]$. It is likely that Tet1, 
as well as $\mathrm{hmC}$, functions in fine-tuning pluripotency in ESCs.

During reprogramming, pluripotency genes that are hypermethylated in somatic cells must be demethylated and activated. Compared with the fast activation of pluripotency genes in SCNT and cell fusion, activation of these genes has substantial latency in the iPSC generation process $[3,4]$. It has been suggested that this difference may be due to the abundance of putative demethylase(s) in oocyte and ESCs. Consistent with this notion, Aid, a deaminase that triggers base excision repair (BER)mediated demethylation by converting $\mathrm{mC}$ to thymidine, has been shown to be required for efficient activation of Oct4 and Nanog in cell fusion-mediated reprogramming [145]. However, it is unclear whether Aid functions similarly in iPSC generation. Nonetheless, insufficient DNA demethylation does pose a hurdle for iPSC generation.

5-Azacytidine (5-Aza), a DNMT inhibitor, facilitates conversion of partially reprogrammed cells to iPSCs, and enhances overall reprogramming efficiency when applied at the late stage of reprogramming [7]. 5-Aza contributes to the reprogramming process presumably by facilitating the demethylation and activation of pluripotency genes. Moreover, a recent study demonstrated that Tet 2 and Parp1, a poly(ADP-ribose) polymerase involved in BERmediated demethylation [146], are required for iPSC generation, and Parp1 overexpression facilitates reprogramming [147]. Mechanistically, Parp1 prevents further methylation of Nanog and Esrrb promoters during reprogramming, while Tet2 deposits hmC on these loci [147]. Parp1- and Tet2-regulated DNA modifications appear to affect the establishment of the active chromatin and the binding of reprogramming factors to Nanog and Esrrb, which eventually contributes to the activation of these pluripotency genes [147]. Although these studies suggest that loss of DNA methylation is an integral part of the reprogramming process, how active DNA demethylation is targeted to the relevant genes remains to be uncovered.

DNA methylation patterns after the establishment of iPSCs Once reprogramming cells gain the self-renewal capacity and become independent of the introduced transcription factors, iPSCs are established. Insufficient DNA demethylation in the reprogramming process also affects the properties of established iPSCs. Remnant DNA methylation patterns specific for the starting cells have been observed in the established iPSCs. This epigenetic memory of the starting cells is associated with biased differentiation potential toward the originating cell lineages $[54,148-150]$. The remnant methylation can be eliminated and the biased potential rectified by serial passages, cross-lineage differentiation, or combined treatment of
DNMT inhibitor and HDAC inhibitor [54, 148]. Moreover, epigenetic memory in iPSCs also reflects in insufficient DNA methylation on somatic-specific gene loci, and such a hypomethylated state is usually associated with transcription aberrancy [151]. Thus, it seems that DNA methylation status needs to be adjusted for nascent iPSCs to reach bona fide pluripotency.

Apart from the remnant somatic cell DNA methylation patterns, multiple reports have shown that certain genomic loci in iPSCs bear aberrant DNA methylation $[12,55$, 152]. Such an aberrant methylation pattern is neither a feature of ESCs nor that of the originating somatic cells. Instead, it is gained through the reprogramming process. Genome-wide single-base mapping of DNA methylation uncovers certain iPSC-specific DNA methylation patterns in human iPSCs $[12,152]$. One study identified nine aberrantly methylated genes that distinguish human iPSCs from human ESCs [152]. A second study showed that the aberrant methylation hotspots in human iPSCs, although mostly occurring at $\mathrm{CpG}$ sites, can be at non$\mathrm{CpG}$ sites around centromeres and telomeres, which may potentially affect chromatin structure [12]. Both studies suggest that the aberrant methylation patterns can be transmitted through differentiation, therefore they may potentially interfere with developmental programs [12, 152]. However, since these analyses are carried out with ESCs and iPSCs with different genetic backgrounds, it is unknown whether and how differences in genetic background contribute to the observed differential DNA methylation patterns between iPSCs and ESCs.

To avoid the potential genetic background effect, a study comparing genetically identical mouse ESCs and iPSCs showed that, an imprinted locus, Dlk1-Dio3, is frequently silenced and hypermethylated during reprogramming [55]. Silencing of this locus in iPSCs is associated with poor success rate in generating all-iPSC mice by tetraploid complementation $[55,153]$. Hypermethylation of this locus depends on the de novo DNA methyltransferase Dnmt3a, and silencing of Dlk1-Dio3 in iPSCs can be overturned by VPA treatment although with a low efficiency [55]. Interestingly, vitamin $\mathrm{C}$ is capable of preventing the aberrant silencing of Dlk1-Dio3 [154]. It is tempting to speculate that silencing of this locus might be counteracted during reprogramming by vitamin Cpromoted activities of the Tet enzymes, which mediate active DNA demethylation.

In summary, a variety of epigenetic mechanisms have different roles in ESC maintenance and during iPSC generation. Epigenetic factors important for sustaining the ESC fate are crucial for iPSC generation, whereas those that barely affect ESC pluripotency and/or self-renewal may also contribute to iPSC generation by affecting the 


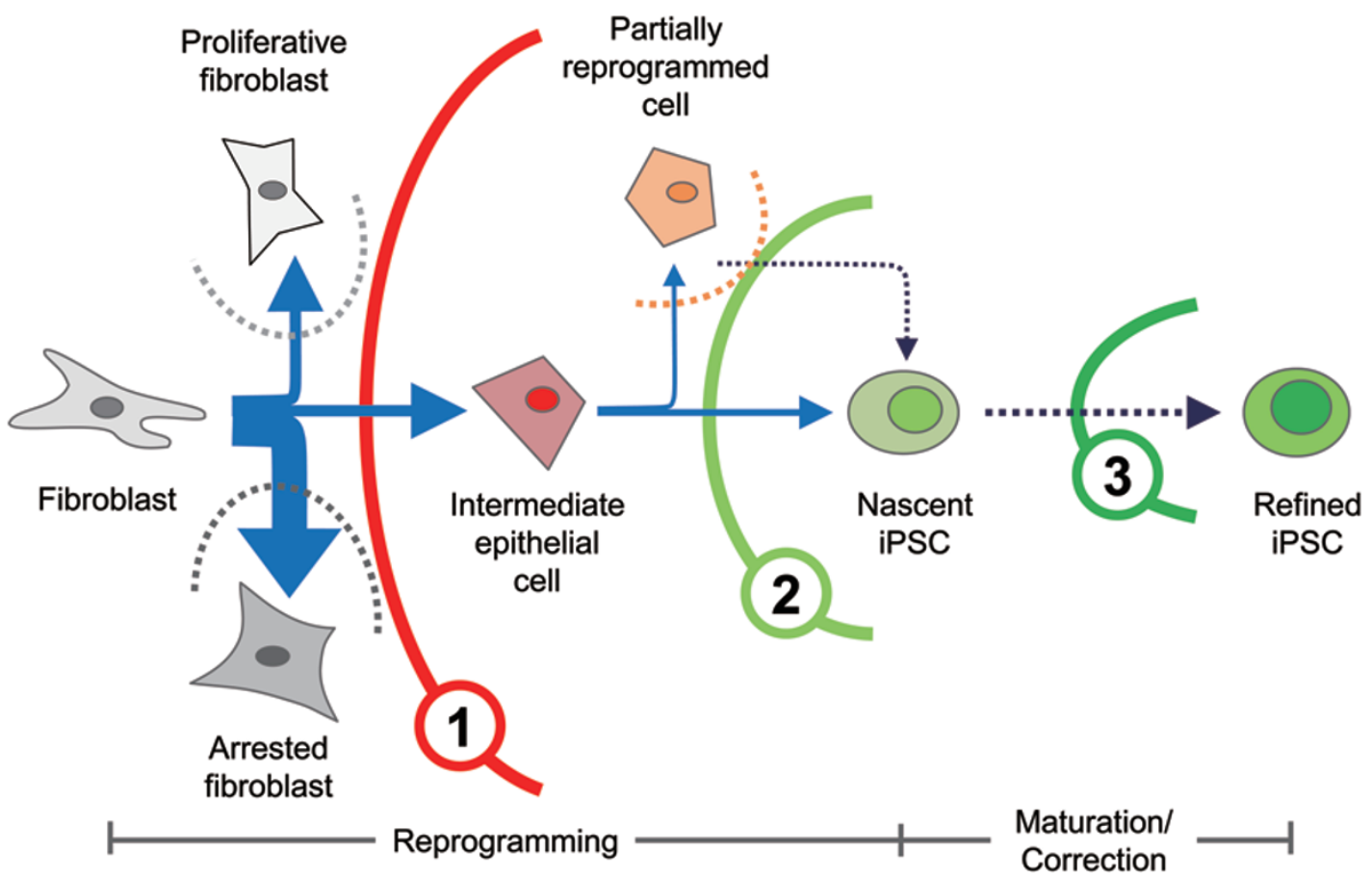

Figure 1 The path from a somatic cell to a refined iPSC and the putative epigenetic barriers during the process. When reprogramming factors are introduced into a fibroblast, the reprogramming factors immediately drive the cell to overcome barrier 1 , resulting in the acquisition of the epithelial properties through MET. A fibroblast that fails to conquer this barrier retains its cellular identity with either an accelerated or arrested proliferation status. After the cell gains epithelial properties, a subsequent barrier (2) to acquiring pluripotency is encountered. Intermediate epithelial cell that successfully overcomes the second barrier becomes a nascent iPSC, which can self-renew independently of introduced transcription factors. Otherwise, it is trapped in the intermediate stage and becomes a partially reprogrammed cell. For the nascent iPSC, additional barrier(s) (3) need to be overcome actively or destructed passively to achieve a bona fide pluripotency equivalent to that in ESCs. Processes that depend on the reprogramming factors are shown in solid arrows, whose thickness reflects the approximate propensity for the cell to undergo a specific transition. Dotted arrows represent the processes that require additional manipulations other than the induction of reprogramming factors. Putative epigenetic barriers in iPSC generation are numbered and shown in solid arcs. Other potential barriers are shown in dotted arcs.

transition of epigenetic landscapes during the reprogramming process.

\section{Mechanisms of iPSC generation}

Reprogramming from somatic cells to an ESC-like state requires elimination of epigenetic marks inherent of somatic cells and establishment of new epigenetic marks characteristic of pluripotency. Each epigenetic event needed to take place in reprogramming can be regarded as an epigenetic barrier. Accumulating evidence indicates that these barriers converge onto two sequential events: (1) MET; and (2) activation of pluripotency circuitry (Figure 1). In addition, nascent iPSCs also need to overcome epigenetic barriers to reach bona fide pluripotency found in ESCs (Figure 1). In this section, we discuss how cell fate conversion is achieved and how reprogramming cells overcome the epigenetic barriers during the iPSC generation process.

Gaining epithelial properties and accelerating cell cycle

Under the influence of reprogramming factors, somatic cells follow a set of steps to achieve pluripotency $[7,107,116,155,156]$. Acquisition of epithelial cell properties through MET is one of the earliest events in reprogramming of somatic cells to iPSCs $[115,116]$. Upregulation of epithelial genes, such as Cdh1 and Epcam, and downregulation of mesenchymal genes, such as Snail/2 and Zeb1/2, take place early in reprogramming $[7,115,116]$. Consistent with this, factors promoting the epithelial state, such as TGF- $\beta$ inhibitors, BMPs, microRNA miR200s and miR302/367, and Cdh1, enhance iPSC generation, and in some cases, are able to substitute for reprogramming factors [116, 157-162]. In contrast, factors that suppress the epithelial state (e.g., TGF- $\beta$ ) or depletion of key epithelial adhesion molecules (e.g., 
Cdh1, Epcam) are able to inhibit iPSC generation [115, $116,160,161]$.

Morphologically, reprograming cells that gain epithelial properties show reduced cell size and compact cellcell interaction $[115,116,163]$. By retrospective image tracing, acquiring epithelial cell-specific morphology is observed for the iPSC-destined cells early in reprogramming. In fact, all iPSCs, indicated by the co-expression of Nanog and Cdh1, are originated from the cells that acquired epithelial features [163]. This observation indicates that acquisition of epithelial status is a necessary step for the establishment of pluripotency in iPSCs.
However, gaining epithelial properties is not sufficient for reaching the iPSC fate, since continuous induction of reprogramming factors is required even after iPSCdestined reprogramming cells have gained the epithelial features $[155,156,163]$. Therefore, additional event(s) that occurs later is also crucial for the establishment of pluripotency. Given that acquisition of epithelial properties is completed early during reprogramming $[115,116$, 163] and able to predict the iPSC-destined cells [163], an elite model for iPSC generation seems reasonable [163]. In this model, the elite status of a certain population of reprogramming cells is imposed at the beginning of re-

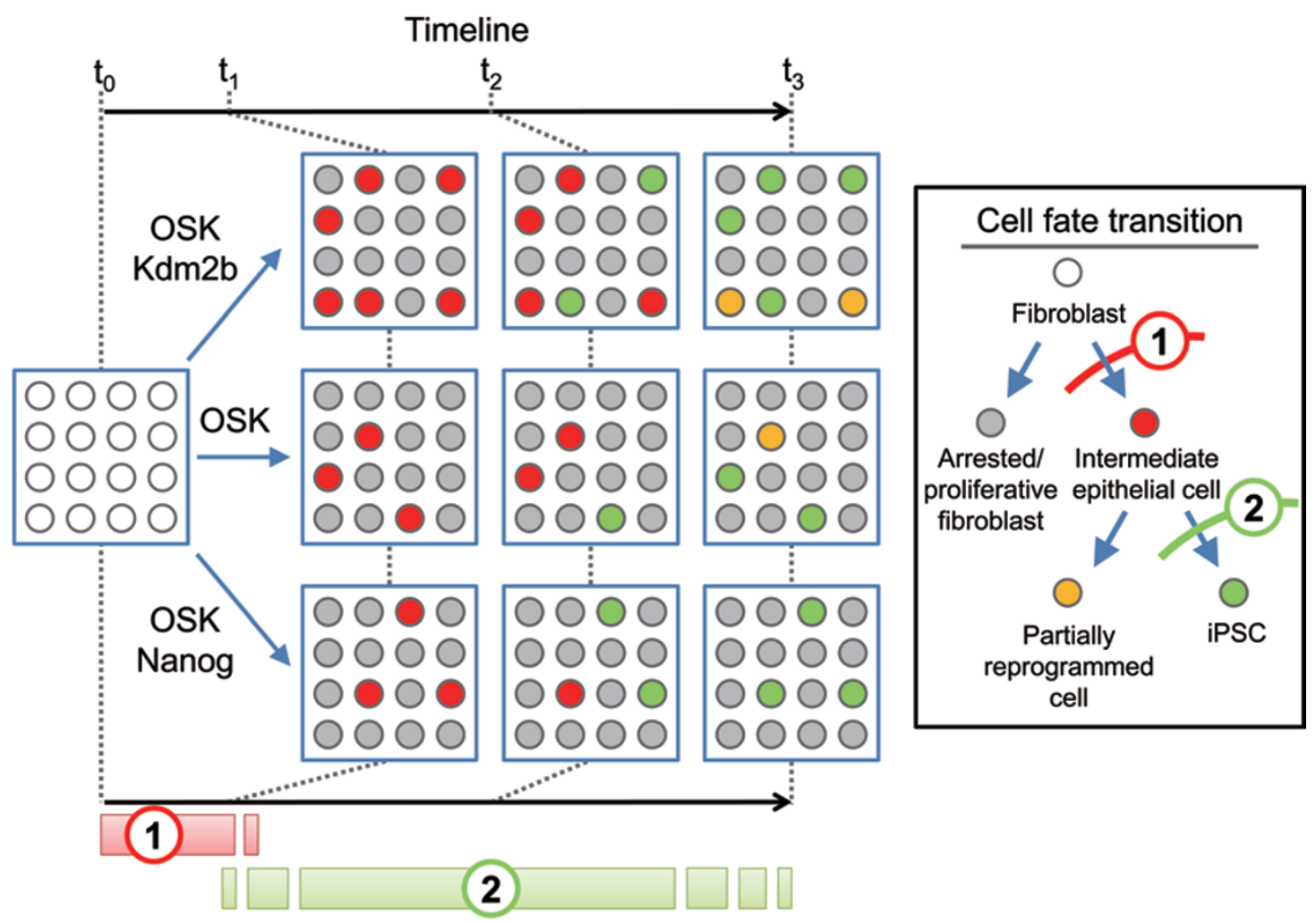

Figure 2 Schematic presentation of a model explaining how iPSC generation can be facilitated by additional factors that act on different steps of the reprogramming process. Reprogramming is initiated at $t_{0}$ by introducing transcription factors Oct4, Sox2 and KIf4 (OSK), OSK plus Kdm2b, or OSK plus Nanog. Soon after reprogramming $\left(t_{1}\right)$, some cells rapidly overcome the putative epigenetic barrier (1) to gain epithelial features. In the presence of $\mathrm{Kdm} 2 \mathrm{~b}$, which facilitates the acquisition of epithelial status [114], more cells overcome this barrier, turning into intermediate epithelial cells. Overcoming this first barrier is depicted in a stochastic manner, although a deterministic mode is also possible. Intermediate cells subsequently encounter the barrier (2) to activating pluripotency circuitry. Overcoming the second barrier may take longer time $\left(t_{1}\right.$ to $t_{2}$ to $\left.t_{3}\right)$ and the task remains incomplete for some cells, which become partially reprogrammed cells. Nanog, which is capable of driving intermediate cells to iPSCs [165], facilitates reprogramming at this step. At certain time points in reprogramming (e.g., from $t_{2}$ to $\left.t_{3}\right)$, the effect of Kdm2b or Nanog is manifested by the increased efficiency in iPSC generation. Different reprogramming factor combinations may also lead to different ratios of partially reprogrammed cells. Note that, cell proliferation and its potential effect on reprogramming are not considered in the figure, since neither Kdm2b nor Nanog enhances reprogramming by affecting the cell cycle $[114,168]$. Cell fate transitions in the reprogramming process are illustrated in the box on the right with putative epigenetic barriers numbered. Bars at the bottom of the figure indicate the progression of iPSC-destined cells in overcoming individual barriers. 
programming either stochastically or deterministically [163]. However, such a model may not fully depict the whole reprogramming process, since it neglects the existence of partially reprogrammed cells, for example, a potential population of $\mathrm{Cdh}^{+} \mathrm{Nanog}^{-}$cells. These partially reprogrammed cells probably gain the epithelial features and form colonies, but fail to activate pluripotency genes [7, 52, 107, 164-166]. A revised model (Figure 2) may present the reprogramming process in a more integral way.

The molecular determinants that endows the reprogramming cells with the advantage in gaining epithelial status, if it exists, need to be determined. At the chromatin level, perturbation of H3K36 and H3K79 methylation statuses may partly account for the advantage of some cells in gaining epithelial statuses $[74,114]$. Determining the binding profiles of the reprogramming factors within the somatic epigenetic landscape will be informative for identifying the rate-limiting epigenetic barriers encountered by these factors in the early step of the iPSC generation process.

Concurrent with gaining epithelial properties, cells that acquire epithelial properties have been shown to escape cell cycle arrest and secure a faster division rate [163]. Several reports showed that promoting cell proliferation, for example, by repressing the p53-p21 pathway or inhibiting Ink4a/Arf, facilitates iPSC generation [167-174]. Along this line, mitosis has been suggested to facilitate reprogramming by promoting the resetting of chromatin states during DNA replication [175]. However, it has also been suggested that faster cell division simply expands the pool of cells that later become iPSCs, as well as cells with other deviated cell fates [163]. Nevertheless, it is not surprising that cell cycle acceleration is not sufficient for driving reprogramming cells to an epithelial state, since a minor percentage of fibroblasts also proliferate faster without transitioning to an epithelial state [163].

Alteration of cell proliferation apparently agrees well with the early reprogramming-induced metabolic changes, which potentially provide the energy needed for the accelerated cell cycle. The metabolic profile of differentiated cells, which favors oxidative phosphorylation, is reset to a glycolysis-dependent ESC-like state after reprogramming [176-180]. This metabolic resetting takes place before pluripotency is established [179]. Manipulating the activities of glycolysis and oxidative phosphorylation affects reprogramming accordingly [176, 179], indicating that metabolic change is also a prerequisite step for pluripotency establishment. c-Myc is likely involved in the immediate cell cycle acceleration and metabolic changes. It has been shown that c-Myc func- tions early during reprogramming and regulates metabolic genes, in particular, glycolysis-related genes, which are not targeted by other reprogramming factors [164]. However, c-Myc is dispensable for iPSC generation [181, 182], and iPSCs derived in the absence of c-Myc bear a similar bioenergetic profile to those reprogrammed with c-Myc [179], suggesting that the introduced pluripotency factors are sufficient for mediating the metabolic changes during reprogramming. Currently, how the metabolic change is achieved, and whether the metabolic change is linked to the concurrent MET process remain to be determined.

\section{Activating pluripotency circuitry}

Compared with the initial step in reprogramming, later events mediating the activation of the pluripotency circuitry in iPSC generation are less characterized. This is in part due to the low efficiency of reprogramming and the cell heterogeneity generated during the reprogramming process. To determine the molecular events leading to pluripotency establishment may require cell purification with available predictive markers or the use of single-cell-based assays. The possibility of the stochastic nature of iPSC generation $[168,183]$ further casts doubt on whether it is possible to define specific molecular events leading to iPSC generation. Nevertheless, several studies have shed some light on the late events in iPSC generation.

Pioneer studies revealed that iPSCs come from the cell population expressing ESC-specific surface marker SSEA-1 $[155,156]$. Unfortunately, the predictability of this marker is low as the majority of SSEA $-1^{+}$cells do not achieve pluripotency [156]. Later work showed that some pluripotency genes, including Nanog, are upregulated soon after epithelial gene activation $[74,114,116$, 158]. The proteins encoded by these early upregulated pluripotency genes may serve as pioneer factors in setting up the pluripotency circuitry. Consistent with this possibility, Nanog has been shown to be essential for the entry to pluripotency $[165,184]$. Specifically, in iPSC generation, Nanog is initially dispensable but takes a pivotal role in driving partially reprogrammed cells into pluripotency [165], and overexpression of Nanog enhances overall reprogramming efficiency [168].

A recent study using single-cell gene expression analysis and clonal retrospective tracing showed that cells destined to iPSCs express a specific set of genes before the pluripotency circuitry is activated [107]. Expression of a set of pluripotency genes, including Esrrb, Utfl, Lin 28 and Dppa2, in clonal cells is strictly correlated with successful derivation of stable iPSC lines [107]. Indeed, iPSC generation can be facilitated by introduc- 
ing Esrrb [185], Utf1 [174], Lin28 [168, 186] or Dppa2 [51], suggesting that these factors may control some rate-limiting step(s) in the reprogramming process. Interestingly, Esrrb, Utf1 and Lin28 are upregulated earlier compared with other pluripotency genes in the bulk of reprogramming cells [116], again suggesting that pioneer expression of some pluripotency genes helps to activate the whole pluripotency circuitry. In addition, other ESCenriched genes, including Fbxo15, Fgf4, and surprisingly Oct4, the commonly used pluripotency marker, can be activated in partially reprogrammed cells that form colonies but fail to become stable iPSCs. Consequently, the expression of these genes does not predict for the iPSC fate [107].

In the same study, an activation hierarchy for pluripotency factors was developed by probabilistic modeling and confirmed by experiments. In this hierarchy, endogenous activation of the Sox 2 locus positions the most upstream and drives the hierarchical activation of a set of pluripotency factors [107]. Such a hierarchy suggests that generation of iPSCs can be achieved by using alternative combinations of reprogramming factors. Indeed, iPSC derivation can be achieved by combinations without any of the original Yamanaka factors, for example, the combination of Lin28, Sall4, Esrrb and Dppa2 [107], suggesting that the pluripotency circuitry can be activated from multiple entry points. In addition, it is a bit puzzling that activation of the endogenous Sox 2 locus positions at the most upstream of the activation hierarchy, considering that Sox 2 is one of the introduced reprogramming factors with a non-physiological expression level in reprogramming cells. We speculate that activation of the endogenous Sox 2 locus likely represents the permissiveness of chromatin environment, at least, at some loci. The permissive chromatin state may lead to the activation of the pluripotency network with the help of the introduced reprogramming factors. In fact, expression of the other pluripotency gene, Nanog, has been shown to take place upon radical chromatin reorganization, and after this the pluripotency is established $[13,14]$.

Overall, at the latter stage of iPSC generation, activation of the pluripotency circuitry takes place through pioneer gene expression and subsequent hierarchical activation of pluripotency genes. The epigenetic barrier restricting the pluripotency establishment in this step is likely reflected in the global non-permissive chromatin configuration and/or the inherent non-permissive chromatin context at the pioneer pluripotency genes. The molecular natures of the epigenetic barriers probably include H3K9me3/2 [13, 14, 71], H3K27me3 [110], insufficient histone acetylation $[25,49,51,52]$, hypermethylation and hypo-hydroxylmethylation on DNA [7, 147], and the lack of proper chromatin remodeling activities [34, 42]. At this point, many questions remain unresolved. For example, what molecular events are required to overcome the potential barriers? Is the success in overcoming the barriers due to the direct effect of the reprogramming factors or the molecular features that are gained from the preceding events (e.g., MET)? Have these barriers overcome in a coordinated way or independently? Is there a rate-limiting barrier? Answering these questions requires detailed study of the chromatin status using pure cell populations or single-cell technologies.

\section{Progression toward bona fide pluripotency}

Upon activation of the pluripotency circuitry, reprogramming cells are able to self-renew independently of the introduced factors. However, these nascent iPSCs may have differential identities distinct from ESCs. First, isolated iPSC lines, at least in low passages, retain some somatic cell memory, which is reflected in the somatic cell gene expression pattern $[9,148,151,187,188]$ and/ or chromatin modification pattern [54, 148-151]. Vestige somatic cell traits need to be removed passively or actively, before nascent iPSCs reach "matured" pluripotency similar to that of ESCs. Second, the established iPSCs may harbor aberrant traits resulted from the reprogramming process. These traits are frequently reflected in aberrant DNA methylation, which can be translated into altered transcription output and/or abnormal functional phenotypes [12, 55, 152]. These aberrant traits may be caused by technical issues, such as stoichiometry of the reprogramming factors used [189] and culturing conditions [190]. Alternatively, they may be intrinsic to the approach of transcription factors-mediated reprogramming. Regardless, this observation argues for the need in optimizing the reprogramming approach.

Despite the documented differences between iPSCs and ESCs, we note that, several analyses suggested that the variable properties of iPSCs may simply reflect the polymorphism of pluripotency that can also be observed among different ESC lines [10, 11, 190]. Nevertheless, further characterization of the polymorphism of pluripotency will enlighten us on how to better harness the therapeutic potential of the pluripotent stem cells.

\section{Concluding remarks}

Epigenetic regulatory mechanisms play important roles in shaping the cellular identity. ESCs provide an invaluable cellular model for understanding the biology of cell-fate control by epigenetic mechanisms; while reprogramming from somatic cells to iPSCs serves as a model system for understanding epigenetic regulations during 
cell fate transition. Characterization of the epigenetic changes and their roles in iPSC generation has provided valuable mechanistic insights into how cell fate change might be achieved. However, our understanding of iPSC generation at the molecular level is hindered by the cell heterogeneity arising from each step of reprogramming and the low percentage of cell population that achieves the iPSC fate. Based on the current understanding of the reprogramming mechanisms, investigation on the cell population enriched by epithelial markers may help elucidate the intermediate events leading to pluripotency. Identification and genetic engineering of stage-specific marker genes that can predict the reprogramming potential will facilitate the studies of molecular events leading to successful iPSC generation. Single-cell-based assays, although in its infancy, have already provided us much mechanistic insight. Analysis of chromatin status at the single-cell level, although technically challenging, will ultimately reveal the epigenetic mechanisms of the reprogramming.

Several recent studies revealed that ESCs have a specialized metabolic profile [176-180]. Interestingly, chromatin modification has also been associated with metabolism in the case of cancer cells [191]. In particular, intermediate metabolites, such as acetyl-CoA, S-adenosylmethionine (SAM) and $\alpha$-ketoglutarate, are cofactors required for acetyltransferases, methyltransferases and dioxygenases, respectively. These enzymes represent a large number of chromatin-modifying enzymes, whose functions in ESCs and iPSC generation are discussed in this review. Most recently, the cellular SAM level, which is controlled by threonine metabolism in ESCs, has been shown to be essential for ESC self-renewal [192]. Threonine turnover sustains the H3K4me3 level in ESCs and supports the robust proliferation and self-renewal of ESCs [192], illustrating the regulatory connections among metabolism, epigenetic modification and pluripotency. It will be intriguing to uncover how these connections are involved in the iPSC generation process.

\section{Acknowledgments}

We would like to thank Shinpei Yamaguchi and Gustavo German for critical reading of this manuscript. We apologize to the people whose work cannot be cited due to space limitation. Stem cell and related work in our lab is supported by NIH (U01DK089565) and HHMI. YZ is an Investigator of the HHMI.

\section{References}

1 Young RA. Control of the embryonic stem cell state. Cell 2011; 144:940-954.

2 Orkin SH, Hochedlinger K. Chromatin connections to plu- ripotency and cellular reprogramming. Cell 2011; 145:835850 .

3 Yamanaka S, Blau HM. Nuclear reprogramming to a pluripotent state by three approaches. Nature 2010; 465:704-712.

4 Pasque V, Jullien J, Miyamoto K, Halley-Stott RP, Gurdon JB. Epigenetic factors influencing resistance to nuclear reprogramming. Trends Genet 2011; 27:516-525.

5 Takahashi K, Yamanaka S. Induction of pluripotent stem cells from mouse embryonic and adult fibroblast cultures by defined factors. Cell 2006; 126:663-676.

6 Maherali N, Sridharan R, Xie W, et al. Directly reprogrammed fibroblasts show global epigenetic remodeling and widespread tissue contribution. Cell Stem Cell 2007; 1:55-70.

7 Mikkelsen TS, Hanna J, Zhang X, et al. Dissecting direct reprogramming through integrative genomic analysis. Nature 2008; 454:49-55.

8 Doi A, Park IH, Wen B, et al. Differential methylation of tissue- and cancer-specific $\mathrm{CpG}$ island shores distinguishes human induced pluripotent stem cells, embryonic stem cells and fibroblasts. Nat Genet 2009; 41:1350-1353.

9 Chin MH, Pellegrini M, Plath K, Lowry WE. Molecular analyses of human induced pluripotent stem cells and embryonic stem cells. Cell Stem Cell 2010; 7:263-269.

10 Guenther MG, Frampton GM, Soldner F, et al. Chromatin structure and gene expression programs of human embryonic and induced pluripotent stem cells. Cell Stem Cell 2010; 7:249-257.

11 Bock C, Kiskinis E, Verstappen G, et al. Reference maps of human ES and iPS cell variation enable high-throughput characterization of pluripotent cell lines. Cell 2011; 144:439452.

12 Lister R, Pelizzola M, Kida YS, et al. Hotspots of aberrant epigenomic reprogramming in human induced pluripotent stem cells. Nature 2011; 471:68-73.

13 Fussner E, Djuric U, Strauss M, et al. Constitutive heterochromatin reorganization during somatic cell reprogramming. EMBO J 2011; 30:1778-1789.

14 Mattout A, Biran A, Meshorer E. Global epigenetic changes during somatic cell reprogramming to iPS cells. $J$ Mol Cell Biol 2011; 3:341-350.

15 Kang L, Wang J, Zhang Y, Kou Z, Gao S. iPS cells can support full-term development of tetraploid blastocyst-complemented embryos. Cell Stem Cell 2009; 5:135-138.

16 Zhao XY, Li W, Lv Z, et al. iPS cells produce viable mice through tetraploid complementation. Nature 2009; 461:8690 .

17 Boland MJ, Hazen JL, Nazor KL, et al. Adult mice generated from induced pluripotent stem cells. Nature 2009; 461:91-94.

18 Stadtfeld M, Hochedlinger K. Induced pluripotency: history, mechanisms, and applications. Genes Dev 2010; 24:22392263.

19 Meshorer E, Yellajoshula D, George E, Scambler PJ, Brown DT, Misteli T. Hyperdynamic plasticity of chromatin proteins in pluripotent embryonic stem cells. Dev Cell 2006; 10:105116.

20 Efroni S, Duttagupta R, Cheng J, et al. Global transcription in pluripotent embryonic stem cells. Cell Stem Cell 2008; 2:437-447.

21 Meshorer E, Misteli T. Chromatin in pluripotent embryonic 
stem cells and differentiation. Nat Rev Mol Cell Biol 2006; 7:540-546

22 Aoto T, Saitoh N, Ichimura T, Niwa H, Nakao M. Nuclear and chromatin reorganization in the MHC-Oct3/4 locus at developmental phases of embryonic stem cell differentiation. Dev Biol 2006; 298:354-367.

23 Hawkins RD, Hon GC, Lee LK, et al. Distinct epigenomic landscapes of pluripotent and lineage-committed human cells. Cell Stem Cell 2010; 6:479-491.

24 Wen B, Wu H, Shinkai Y, Irizarry RA, Feinberg AP. Large histone H3 lysine 9 dimethylated chromatin blocks distinguish differentiated from embryonic stem cells. Nat Genet 2009; 41:246-250.

25 Li X, Li L, Pandey R, et al. The histone acetyltransferase $\mathrm{MOF}$ is a key regulator of the embryonic stem cell core transcriptional network. Cell Stem Cell 2012; 11:163-178.

26 Krejci J, Uhlirova R, Galiova G, Kozubek S, Smigova J, Bartova E. Genome-wide reduction in $\mathrm{H} 3 \mathrm{~K} 9$ acetylation during human embryonic stem cell differentiation. J Cell Physiol 2009; 219:677-687.

27 Koche RP, Smith ZD, Adli M, et al. Reprogramming factor expression initiates widespread targeted chromatin remodeling. Cell Stem Cell 2011; 8:96-105.

28 Ho L, Crabtree GR. Chromatin remodelling during development. Nature 2010; 463:474-484.

29 Ho L, Ronan JL, Wu J, et al. An embryonic stem cell chromatin remodeling complex, esBAF, is essential for embryonic stem cell self-renewal and pluripotency. Proc Natl Acad Sci USA 2009; 106:5181-5186.

30 Gao X, Tate P, Hu P, Tjian R, Skarnes WC, Wang Z. ES cell pluripotency and germ-layer formation require the SWI/SNF chromatin remodeling component BAF250a. Proc Natl Acad Sci USA 2008; 105:6656-6661.

31 Yan Z, Wang Z, Sharova L, et al. BAF250B-associated SWI/ SNF chromatin-remodeling complex is required to maintain undifferentiated mouse embryonic stem cells. Stem Cells 2008; 26:1155-1165.

32 Kidder BL, Palmer S, Knott JG. SWI/SNF-Brg1 regulates self-renewal and occupies core pluripotency-related genes in embryonic stem cells. Stem Cells 2009; 27:317-328.

33 Ho L, Jothi R, Ronan JL, Cui K, Zhao K, Crabtree GR. An embryonic stem cell chromatin remodeling complex, esBAF, is an essential component of the core pluripotency transcriptional network. Proc Natl Acad Sci USA 2009; 106:51875191.

34 Ho L, Miller EL, Ronan JL, Ho WQ, Jothi R, Crabtree GR. esBAF facilitates pluripotency by conditioning the genome for LIF/STAT3 signalling and by regulating polycomb function. Nat Cell Biol 2011; 13:903-913.

35 Singhal N, Graumann J, Wu G, et al. Chromatin-remodeling components of the BAF complex facilitate reprogramming. Cell 2010; 141:943-955.

36 Gaspar-Maia A, Alajem A, Polesso F, et al. Chd1 regulates open chromatin and pluripotency of embryonic stem cells. Nature 2009; 460:863-868.

37 Yildirim $\mathrm{O}$, Li R, Hung JH, et al. Mbd3/NURD complex regulates expression of 5-hydroxymethylcytosine marked genes in embryonic stem cells. Cell 2011; 147:1498-1510.

38 Whyte WA, Bilodeau S, Orlando DA, et al. Enhancer decom- missioning by LSD1 during embryonic stem cell differentiation. Nature 2012; 482:221-225.

39 Reynolds N, Salmon-Divon M, Dvinge H, et al. NuRDmediated deacetylation of $\mathrm{H} 3 \mathrm{~K} 27$ facilitates recruitment of polycomb repressive complex 2 to direct gene repression. EMBO J 2012; 31:593-605.

40 Kaji K, Caballero IM, MacLeod R, Nichols J, Wilson VA, Hendrich B. The NuRD component Mbd3 is required for pluripotency of embryonic stem cells. Nat Cell Biol 2006; 8:285-292.

41 Reynolds N, Latos P, Hynes-Allen A, et al. NuRD suppresses pluripotency gene expression to promote transcriptional heterogeneity and lineage commitment. Cell Stem Cell 2012; 10:583-594.

42 Fidalgo M, Faiola F, Pereira CF, et al. Zfp281 mediates Nanog autorepression through recruitment of the NuRD complex and inhibits somatic cell reprogramming. Proc Natl Acad Sci USA 2012; 109:16202-16207.

43 Fazzio TG, Huff JT, Panning B. An RNAi screen of chromatin proteins identifies Tip60-p400 as a regulator of embryonic stem cell identity. Cell 2008; 134:162-174.

44 Landry J, Sharov AA, Piao Y, et al. Essential role of chromatin remodeling protein Bptf in early mouse embryos and embryonic stem cells. PLoS Genet 2008; 4:e1000241.

45 Kouzarides T. Chromatin modifications and their function. Cell 2007; 128:693-705.

46 Melcer S, Hezroni H, Rand E, et al. Histone modifications and lamin A regulate chromatin protein dynamics in early embryonic stem cell differentiation. Nat Commun 2012; 3:910.

47 Ware CB, Wang L, Mecham BH, et al. Histone deacetylase inhibition elicits an evolutionarily conserved self-renewal program in embryonic stem cells. Cell Stem Cell 2009; 4:359-369.

48 Hezroni H, Tzchori I, Davidi A, et al. H3K9 histone acetylation predicts pluripotency and reprogramming capacity of ES cells. Nucleus 2011; 2:300-309.

49 Huangfu D, Maehr R, Guo W, et al. Induction of pluripotent stem cells by defined factors is greatly improved by smallmolecule compounds. Nat Biotechnol 2008; 26:795-797.

50 Huangfu D, Osafune K, Maehr R, et al. Induction of pluripotent stem cells from primary human fibroblasts with only Oct4 and Sox2. Nat Biotechnol 2008; 26:1269-1275.

51 Mali P, Chou BK, Yen J, et al. Butyrate greatly enhances derivation of human induced pluripotent stem cells by promoting epigenetic remodeling and the expression of pluripotency-associated genes. Stem Cells 2010; 28:713-720.

52 Liang G, Taranova O, Xia K, Zhang Y. Butyrate promotes induced pluripotent stem cell generation. J Biol Chem 2010; 285:25516-25521.

53 Anokye-Danso F, Trivedi CM, Juhr D, et al. Highly efficient miRNA-mediated reprogramming of mouse and human somatic cells to pluripotency. Cell Stem Cell 2011; 8:376-388.

54 Kim K, Doi A, Wen B, et al. Epigenetic memory in induced pluripotent stem cells. Nature 2010; 467:285-290.

55 Stadtfeld M, Apostolou E, Akutsu H, et al. Aberrant silencing of imprinted genes on chromosome $12 \mathrm{qF} 1$ in mouse induced pluripotent stem cells. Nature 2010; 465:175-181.

56 Dou Y, Milne TA, Tackett AJ, et al. Physical association and 
coordinate function of the $\mathrm{H} 3 \mathrm{~K} 4$ methyltransferase MLL1 and the H4 K16 acetyltransferase MOF. Cell 2005; 121:873885.

57 Ang YS, Tsai SY, Lee DF, et al. Wdr5 mediates self-renewal and reprogramming via the embryonic stem cell core transcriptional network. Cell 2011; 145:183-197.

58 Jiang H, Shukla A, Wang X, Chen WY, Bernstein BE, Roeder RG. Role for Dpy-30 in ES cell-fate specification by regulation of $\mathrm{H} 3 \mathrm{~K} 4$ methylation within bivalent domains. Cell 2011; 144:513-525.

59 Li B, Carey M, Workman JL. The role of chromatin during transcription. Cell 2007; 128:707-719.

60 Bernstein BE, Meissner A, Lander ES. The mammalian epigenome. Cell 2007; 128:669-681.

61 Nguyen AT, Zhang Y. The diverse functions of Dot1 and H3K79 methylation. Genes Dev 2011; 25:1345-1358.

62 Greer EL, Shi Y. Histone methylation: a dynamic mark in health, disease and inheritance. Nat Rev Genet 2012; 13:343357.

63 Guenther MG, Levine SS, Boyer LA, Jaenisch R, Young RA. A chromatin landmark and transcription initiation at most promoters in human cells. Cell 2007; 130:77-88.

64 Heintzman ND, Stuart RK, Hon G, et al. Distinct and predictive chromatin signatures of transcriptional promoters and enhancers in the human genome. Nat Genet 2007; 39:311318.

65 Min IM, Waterfall JJ, Core LJ, Munroe RJ, Schimenti J, Lis JT. Regulating RNA polymerase pausing and transcription elongation in embryonic stem cells. Genes Dev 2011; 25:742-754.

66 Rahl PB, Lin CY, Seila AC, et al. c-Myc regulates transcriptional pause release. Cell 2010; 141:432-445.

67 Mikkelsen TS, Ku M, Jaffe DB, et al. Genome-wide maps of chromatin state in pluripotent and lineage-committed cells. Nature 2007; 448:553-560.

68 Adamo A, Sese B, Boue S, et al. LSD1 regulates the balance between self-renewal and differentiation in human embryonic stem cells. Nat Cell Biol 2011; 13:652-659.

69 Xie L, Pelz C, Wang W, et al. KDM5B regulates embryonic stem cell self-renewal and represses cryptic intragenic transcription. EMBO J 2011; 30:1473-1484.

70 Epsztejn-Litman S, Feldman N, Abu-Remaileh M, et al. De novo DNA methylation promoted by G9a prevents reprogramming of embryonically silenced genes. Nat Struct Mol Biol 2008; 15:1176-1183.

71 Loh YH, Zhang W, Chen X, George J, Ng HH. Jmjd1a and Jmjd2c histone H3 Lys 9 demethylases regulate self-renewal in embryonic stem cells. Genes Dev 2007; 21:2545-2557.

72 Ma DK, Chiang CH, Ponnusamy K, Ming GL, Song H. G9a and $\mathrm{Jhdm} 2 \mathrm{a}$ regulate embryonic stem cell fusion-induced reprogramming of adult neural stem cells. Stem Cells 2008; 26:2131-2141.

73 Shi Y, Do JT, Desponts C, Hahm HS, Scholer HR, Ding S. A combined chemical and genetic approach for the generation of induced pluripotent stem cells. Cell Stem Cell 2008; 2:525-528.

74 Onder TT, Kara N, Cherry A, et al. Chromatin-modifying enzymes as modulators of reprogramming. Nature 2012; 483:598-602.
75 Lohmann F, Loureiro J, Su H, et al. KMT1E mediated H3K9 methylation is required for the maintenance of embryonic stem cells by repressing trophectoderm differentiation. Stem Cells 2010; 28:201-212.

76 Bilodeau S, Kagey MH, Frampton GM, Rahl PB, Young RA. SetDB1 contributes to repression of genes encoding developmental regulators and maintenance of ES cell state. Genes Dev 2009; 23:2484-2489.

77 Yeap LS, Hayashi K, Surani MA. ERG-associated protein with SET domain (ESET)-Oct4 interaction regulates pluripotency and represses the trophectoderm lineage. Epigenetics Chromatin 2009; 2:12.

78 Yuan P, Han J, Guo G, et al. Eset partners with Oct4 to restrict extraembryonic trophoblast lineage potential in embryonic stem cells. Genes Dev 2009; 23:2507-2520.

79 Bernstein BE, Mikkelsen TS, Xie X, et al. A bivalent chromatin structure marks key developmental genes in embryonic stem cells. Cell 2006; 125:315-326.

80 Azuara V, Perry P, Sauer S, et al. Chromatin signatures of pluripotent cell lines. Nat Cell Biol 2006; 8:532-538.

81 Pan G, Tian S, Nie J, et al. Whole-genome analysis of histone $\mathrm{H} 3$ lysine 4 and lysine 27 methylation in human embryonic stem cells. Cell Stem Cell 2007; 1:299-312.

82 Zhao XD, Han X, Chew JL, et al. Whole-genome mapping of histone H3 Lys4 and 27 trimethylations reveals distinct genomic compartments in human embryonic stem cells. Cell Stem Cell 2007; 1:286-298.

83 Boyer LA, Plath K, Zeitlinger J, et al. Polycomb complexes repress developmental regulators in murine embryonic stem cells. Nature 2006; 441:349-353.

84 Bracken AP, Dietrich N, Pasini D, Hansen KH, Helin K. Genome-wide mapping of Polycomb target genes unravels their roles in cell fate transitions. Genes Dev 2006; 20:11231136.

85 Lee TI, Jenner RG, Boyer LA, et al. Control of developmental regulators by Polycomb in human embryonic stem cells. Cell 2006; 125:301-313.

86 Peng JC, Valouev A, Swigut T, et al. Jarid2/Jumonji coordinates control of PRC2 enzymatic activity and target gene occupancy in pluripotent cells. Cell 2009; 139:1290-1302.

87 Shen X, Kim W, Fujiwara Y, et al. Jumonji modulates polycomb activity and self-renewal versus differentiation of stem cells. Cell 2009; 139:1303-1314.

88 Landeira D, Sauer S, Poot R, et al. Jarid2 is a PRC2 component in embryonic stem cells required for multi-lineage differentiation and recruitment of PRC1 and RNA Polymerase II to developmental regulators. Nat Cell Biol 2010; 12:618624.

89 Pasini D, Cloos PA, Walfridsson J, et al. JARID2 regulates binding of the Polycomb repressive complex 2 to target genes in ES cells. Nature 2010; 464:306-310.

90 Li G, Margueron R, Ku M, Chambon P, Bernstein BE, Reinberg D. Jarid2 and PRC2, partners in regulating gene expression. Genes Dev 2010; 24:368-380.

91 Walker E, Manias JL, Chang WY, Stanford WL. PCL2 modulates gene regulatory networks controlling self-renewal and commitment in embryonic stem cells. Cell Cycle 2011; 10:45-51.

92 Endoh M, Endo TA, Endoh T, et al. Polycomb group proteins 
Ring1A/B are functionally linked to the core transcriptional regulatory circuitry to maintain ES cell identity. Development 2008; 135:1513-1524.

$93 \mathrm{Ku} \mathrm{M}$, Koche RP, Rheinbay E, et al. Genomewide analysis of PRC1 and PRC2 occupancy identifies two classes of bivalent domains. PLoS Genet 2008; 4:e1000242.

94 Pasini D, Bracken AP, Hansen JB, Capillo M, Helin K. The polycomb group protein Suz12 is required for embryonic stem cell differentiation. Mol Cell Biol 2007; 27:3769-3779.

95 Leeb M, Pasini D, Novatchkova M, Jaritz M, Helin K, Wutz A. Polycomb complexes act redundantly to repress genomic repeats and genes. Genes Dev 2010; 24:265-276.

96 Chamberlain SJ, Yee D, Magnuson T. Polycomb repressive complex 2 is dispensable for maintenance of embryonic stem cell pluripotency. Stem Cells 2008; 26:1496-1505.

97 Shen X, Liu Y, Hsu YJ, et al. EZH1 mediates methylation on histone $\mathrm{H} 3$ lysine 27 and complements EZH2 in maintaining stem cell identity and executing pluripotency. Mol Cell 2008; 32:491-502.

98 O'Carroll D, Erhardt S, Pagani M, Barton SC, Surani MA, Jenuwein T. The polycomb-group gene Ezh2 is required for early mouse development. Mol Cell Biol 2001; 21:43304336.

99 Pasini D, Bracken AP, Jensen MR, Lazzerini Denchi E, Helin K. Suz12 is essential for mouse development and for EZH2 histone methyltransferase activity. EMBO J 2004; 23:40614071.

100 Faust C, Schumacher A, Holdener B, Magnuson T. The eed mutation disrupts anterior mesoderm production in mice. Development 1995; 121:273-285.

101 Voncken JW, Roelen BA, Roefs M, et al. Rnf2 (Ring1b) deficiency causes gastrulation arrest and cell cycle inhibition. Proc Natl Acad Sci USA 2003; 100:2468-2473.

102 Roh TY, Cuddapah S, Cui K, Zhao K. The genomic landscape of histone modifications in human T cells. Proc Natl Acad Sci USA 2006; 103:15782-15787.

103 Barski A, Cuddapah S, Cui K, et al. High-resolution profiling of histone methylations in the human genome. Cell 2007; 129:823-837.

104 Marks H, Kalkan T, Menafra R, et al. The transcriptional and epigenomic foundations of ground state pluripotency. Cell 2012; 149:590-604.

105 Yuan W, Wu T, Fu H, et al. Dense chromatin activates Polycomb repressive complex 2 to regulate H3 lysine 27 methylation. Science 2012; 337:971-975.

106 Pereira CF, Piccolo FM, Tsubouchi T, et al. ESCs require PRC2 to direct the successful reprogramming of differentiated cells toward pluripotency. Cell Stem Cell 2010; 6:547556.

107 Buganim Y, Faddah DA, Cheng AW, et al. Single-cell expression analyses during cellular reprogramming reveal an early stochastic and a late hierarchic phase. Cell 2012; 150:12091222 .

108 Zhang Z, Jones A, Sun CW, et al. PRC2 complexes with JARID2, MTF2, and esPRC2p48 in ES cells to modulate ES cell pluripotency and somatic cell reprogramming. Stem Cells 2011; 29:229-240.

109 Moon JH, Heo JS, Kim JS, et al. Reprogramming fibroblasts into induced pluripotent stem cells with Bmil. Cell Res
2011; 21:1305-1315.

110 Mansour AA, Gafni O, Weinberger L, et al. The H3K27 demethylase Utx regulates somatic and germ cell epigenetic reprogramming. Nature 2012; 488:409-413.

111 Lee S, Lee JW, Lee SK. UTX, a histone H3-lysine 27 demethylase, acts as a critical switch to activate the cardiac developmental program. Dev Cell 2012; 22:25-37.

112 Blackledge NP, Zhou JC, Tolstorukov MY, Farcas AM, Park PJ, Klose RJ. CpG islands recruit a histone H3 lysine 36 demethylase. Mol Cell 2010; 38:179-190.

113 Wang T, Chen K, Zeng X, et al. The histone demethylases $\mathrm{Jhdm} 1 \mathrm{a} / 1 \mathrm{~b}$ enhance somatic cell reprogramming in a vitamin-C-dependent manner. Cell Stem Cell 2011; 9:575-587.

114 Liang G, He J, Zhang Y. Kdm2b promotes induced pluripotent stem cell generation by facilitating gene activation early in reprogramming. Nat Cell Biol 2012; 14:457-466.

115 Li R, Liang J, Ni S, et al. A mesenchymal-to-epithelial transition initiates and is required for the nuclear reprogramming of mouse fibroblasts. Cell Stem Cell 2010; 7:51-63.

116 Samavarchi-Tehrani P, Golipour A, David L, et al. Functional genomics reveals a BMP-driven mesenchymal-to-epithelial transition in the initiation of somatic cell reprogramming. Cell Stem Cell 2010; 7:64-77.

117 McDonald OG, Wu H, Timp W, Doi A, Feinberg AP. Genome-scale epigenetic reprogramming during epithelial-tomesenchymal transition. Nat Struct Mol Biol 2011; 18:867874.

118 Miller DM, Buettner GR, Aust SD. Transition metals as catalysts of "autoxidation" reactions. Free Radic Biol Med 1990; 8:95-108.

119 Tsukada Y, Fang J, Erdjument-Bromage H, et al. Histone demethylation by a family of JmjC domain-containing proteins. Nature 2006; 439:811-816.

120 He J, Kallin EM, Tsukada Y, Zhang Y. The H3K36 demethylase $\mathrm{Jhdm} 1 \mathrm{~b} / \mathrm{Kdm} 2 \mathrm{~b}$ regulates cell proliferation and senescence through p15(Ink4b). Nat Struct Mol Biol 2008; 15:1169-1175.

121 Esteban MA, Wang T, Qin B, et al. Vitamin C enhances the generation of mouse and human induced pluripotent stem cells. Cell Stem Cell 2010; 6:71-79.

122 Jones B, Su H, Bhat A, et al. The histone H3K79 methyltransferase Dot1L is essential for mammalian development and heterochromatin structure. PLoS Genet 2008; 4:e1000190.

123 Bird A. DNA methylation patterns and epigenetic memory. Genes Dev 2002; 16:6-21.

124 Meissner A, Mikkelsen TS, Gu H, et al. Genome-scale DNA methylation maps of pluripotent and differentiated cells. $\mathrm{Na}$ ture 2008; 454:766-770.

125 Mohn F, Weber M, Rebhan M, et al. Lineage-specific polycomb targets and de novo DNA methylation define restriction and potential of neuronal progenitors. Mol Cell 2008; 30:755-766.

126 Fouse SD, Shen Y, Pellegrini M, et al. Promoter CpG methylation contributes to ES cell gene regulation in parallel with Oct4/Nanog, PcG complex, and histone H3 K4/K27 trimethylation. Cell Stem Cell 2008; 2:160-169.

127 Farthing CR, Ficz G, Ng RK, et al. Global mapping of DNA methylation in mouse promoters reveals epigenetic 
reprogramming of pluripotency genes. PLoS Genet 2008; 4:e1000116.

128 Li E, Bestor TH, Jaenisch R. Targeted mutation of the DNA methyltransferase gene results in embryonic lethality. Cell 1992; 69:915-926.

129 Okano M, Bell DW, Haber DA, Li E. DNA methyltransferases Dnmt3a and Dnmt3b are essential for de novo methylation and mammalian development. Cell 1999; 99:247-257.

130 Tsumura A, Hayakawa T, Kumaki Y, et al. Maintenance of self-renewal ability of mouse embryonic stem cells in the absence of DNA methyltransferases Dnmt1, Dnmt3a and Dnmt3b. Genes Cells 2006; 11:805-814.

131 Jackson M, Krassowska A, Gilbert N, et al. Severe global DNA hypomethylation blocks differentiation and induces histone hyperacetylation in embryonic stem cells. Mol Cell Biol 2004; 24:8862-8871.

132 Pawlak M, Jaenisch R. De novo DNA methylation by Dn$\mathrm{mt} 3 \mathrm{a}$ and Dnmt $3 \mathrm{~b}$ is dispensable for nuclear reprogramming of somatic cells to a pluripotent state. Genes Dev 2011; 25:1035-1040.

133 Wu SC, Zhang Y. Active DNA demethylation: many roads lead to Rome. Nat Rev Mol Cell Biol 2010; 11:607-620.

134 Tahiliani M, Koh KP, Shen Y, et al. Conversion of 5-methylcytosine to 5-hydroxymethylcytosine in mammalian DNA by MLL partner TET1. Science 2009; 324:930-935.

135 Ito S, D'Alessio AC, Taranova OV, Hong K, Sowers LC, Zhang Y. Role of Tet proteins in $5 \mathrm{mC}$ to $5 \mathrm{hmC}$ conversion, ES-cell self-renewal and inner cell mass specification. Nature 2010; 466:1129-1133.

136 Ito S, Shen L, Dai Q, et al. Tet proteins can convert 5-methylcytosine to 5-formylcytosine and 5-carboxylcytosine. Science 2011; 333:1300-1303.

137 He YF, Li BZ, Li Z, et al. Tet-mediated formation of 5-carboxylcytosine and its excision by TDG in mammalian DNA. Science 2011; 333:1303-1307.

$138 \mathrm{Wu} \mathrm{H}$, D'Alessio AC, Ito S, et al. Dual functions of Tet1 in transcriptional regulation in mouse embryonic stem cells. Nature 2011; 473:389-393.

$139 \mathrm{Xu} \mathrm{Y,} \mathrm{Wu} \mathrm{F,} \mathrm{Tan} \mathrm{L,} \mathrm{et} \mathrm{al.} \mathrm{Genome-wide} \mathrm{regulation} \mathrm{of} \mathrm{5hmC,}$ $5 \mathrm{mC}$, and gene expression by Tet1 hydroxylase in mouse embryonic stem cells. Mol Cell 2011; 42:451-464.

140 Williams K, Christensen J, Pedersen MT, et al. TET1 and hydroxymethylcytosine in transcription and DNA methylation fidelity. Nature 2011; 473:343-348.

141 Pastor WA, Pape UJ, Huang Y, et al. Genome-wide mapping of 5-hydroxymethylcytosine in embryonic stem cells. Nature 2011; 473:394-397.

142 Ficz G, Branco MR, Seisenberger S, et al. Dynamic regulation of 5-hydroxymethylcytosine in mouse ES cells and during differentiation. Nature 2011; 473:398-402.

143 Dawlaty MM, Ganz K, Powell BE, et al. Tet1 is dispensable for maintaining pluripotency and its loss is compatible with embryonic and postnatal development. Cell Stem Cell 2011; 9:166-175.

144 Koh KP, Yabuuchi A, Rao S, et al. Tet1 and Tet2 regulate 5-hydroxymethylcytosine production and cell lineage specification in mouse embryonic stem cells. Cell Stem Cell 2011; 8:200-213.

145 Bhutani N, Brady JJ, Damian M, Sacco A, Corbel SY, Blau
HM. Reprogramming towards pluripotency requires AID-dependent DNA demethylation. Nature 2010; 463:1042-1047.

146 Auberlet JM, Pacaux MP, Anceaux F, Plainchault P, Rosey F. The impact of perceptual treatments on lateral control: a study using fixed-base and motion-base driving simulators. Accid Anal Prev 2010; 42:166-173.

147 Doege CA, Inoue K, Yamashita T, et al. Early-stage epigenetic modification during somatic cell reprogramming by Parp1 and Tet2. Nature 2012; 488:652-655.

148 Polo JM, Liu S, Figueroa ME, et al. Cell type of origin influences the molecular and functional properties of mouse induced pluripotent stem cells. Nat Biotechnol 2010; 28:848855.

149 Kim K, Zhao R, Doi A, et al. Donor cell type can influence the epigenome and differentiation potential of human induced pluripotent stem cells. Nat Biotechnol 2011; 29:11171119.

150 Bar-Nur O, Russ HA, Efrat S, Benvenisty N. Epigenetic memory and preferential lineage-specific differentiation in induced pluripotent stem cells derived from human pancreatic islet beta cells. Cell Stem Cell 2011; 9:17-23.

151 Ohi Y, Qin H, Hong C, et al. Incomplete DNA methylation underlies a transcriptional memory of somatic cells in human iPS cells. Nat Cell Biol 2011; 13:541-549.

152 Ruiz S, Diep D, Gore A, et al. Identification of a specific reprogramming-associated epigenetic signature in human induced pluripotent stem cells. Proc Natl Acad Sci USA 2012; 109:16196-16201.

153 Liu L, Luo GZ, Yang W, et al. Activation of the imprinted Dlk1-Dio3 region correlates with pluripotency levels of mouse stem cells. J Biol Chem 2010; 285:19483-19490.

154 Stadtfeld M, Apostolou E, Ferrari F, et al. Ascorbic acid prevents loss of Dlk1-Dio3 imprinting and facilitates generation of all-iPS cell mice from terminally differentiated B cells. Nat Genet 2012; 44:398-405.

155 Brambrink T, Foreman R, Welstead GG, et al. Sequential expression of pluripotency markers during direct reprogramming of mouse somatic cells. Cell Stem Cell 2008; 2:151-159.

156 Stadtfeld M, Maherali N, Breault DT, Hochedlinger K. Defining molecular cornerstones during fibroblast to iPS cell reprogramming in mouse. Cell Stem Cell 2008; 2:230-240.

157 Liao B, Bao X, Liu L, et al. MicroRNA cluster 302-367 enhances somatic cell reprogramming by accelerating a mesenchymal-to-epithelial transition. J Biol Chem 2011; 286:17359-17364.

158 Ichida JK, Blanchard J, Lam K, et al. A small-molecule inhibitor of tgf-Beta signaling replaces sox 2 in reprogramming by inducing nanog. Cell Stem Cell 2009; 5:491-503.

159 Maherali N, Hochedlinger K. TGFbeta signal inhibition cooperates in the induction of iPSCs and replaces Sox 2 and cMyc. Curr Biol 2009; 19:1718-1723.

160 Chen T, Yuan D, Wei B, et al. E-cadherin-mediated cell-cell contact is critical for induced pluripotent stem cell generation. Stem Cells 2010; 28:1315-1325.

161 Redmer T, Diecke S, Grigoryan T, Quiroga-Negreira A, Birchmeier W, Besser D. E-cadherin is crucial for embryonic stem cell pluripotency and can replace OCT4 during somatic cell reprogramming. EMBO Rep 2011; 12:720-726.

162 Chen J, Liu J, Yang J, et al. BMPs functionally replace Klf4 
and support efficient reprogramming of mouse fibroblasts by Oct4 alone. Cell Res 2011; 21:205-212.

163 Smith ZD, Nachman I, Regev A, Meissner A. Dynamic single-cell imaging of direct reprogramming reveals an early specifying event. Nat Biotechnol 2010; 28:521-526.

164 Sridharan R, Tchieu J, Mason MJ, et al. Role of the murine reprogramming factors in the induction of pluripotency. Cell 2009; 136:364-377.

165 Silva J, Nichols J, Theunissen TW, et al. Nanog is the gateway to the pluripotent ground state. Cell 2009; 138:722-737.

166 Silva J, Barrandon O, Nichols J, Kawaguchi J, Theunissen TW, Smith A. Promotion of reprogramming to ground state pluripotency by signal inhibition. PLoS Biol 2008; 6:e253.

167 Li H, Collado M, Villasante A, et al. The Ink4/Arf locus is a barrier for iPS cell reprogramming. Nature 2009; 460:11361139.

168 Hanna J, Saha K, Pando B, et al. Direct cell reprogramming is a stochastic process amenable to acceleration. Nature 2009; 462:595-601.

169 Utikal J, Polo JM, Stadtfeld M, et al. Immortalization eliminates a roadblock during cellular reprogramming into iPS cells. Nature 2009; 460:1145-1148.

170 Hong H, Takahashi K, Ichisaka T, et al. Suppression of induced pluripotent stem cell generation by the p53-p21 pathway. Nature 2009; 460:1132-1135.

171 Kawamura T, Suzuki J, Wang YV, et al. Linking the p53 tumour suppressor pathway to somatic cell reprogramming. Nature 2009; 460:1140-1144.

172 Banito A, Rashid ST, Acosta JC, et al. Senescence impairs successful reprogramming to pluripotent stem cells. Genes Dev 2009; 23:2134-2139.

173 Marion RM, Strati K, Li H, et al. A p53-mediated DNA damage response limits reprogramming to ensure iPS cell genomic integrity. Nature 2009; 460:1149-1153.

174 Zhao Y, Yin X, Qin H, et al. Two supporting factors greatly improve the efficiency of human iPSC generation. Cell Stem Cell 2008; 3:475-479.

175 Egli D, Birkhoff G, Eggan K. Mediators of reprogramming: transcription factors and transitions through mitosis. Nat Rev Mol Cell Biol 2008; 9:505-516.

176 Panopoulos AD, Yanes O, Ruiz S, et al. The metabolome of induced pluripotent stem cells reveals metabolic changes occurring in somatic cell reprogramming. Cell Res 2012; 22:168-177.

177 Zhang J, Khvorostov I, Hong JS, et al. UCP2 regulates energy metabolism and differentiation potential of human pluripotent stem cells. EMBO J 2011; 30:4860-4873.

178 Prigione A, Fauler B, Lurz R, Lehrach H, Adjaye J. The senescence-related mitochondrial/oxidative stress pathway is repressed in human induced pluripotent stem cells. Stem Cells 2010; 28:721-733.

179 Folmes CD, Nelson TJ, Martinez-Fernandez A, et al. Somatic oxidative bioenergetics transitions into pluripotencydependent glycolysis to facilitate nuclear reprogramming. Cell Metab 2011; 14:264-271.

180 Varum S, Rodrigues AS, Moura MB, et al. Energy metabolism in human pluripotent stem cells and their differentiated counterparts. PLoS One 2011; 6:e20914.

181 Wernig M, Meissner A, Cassady JP, Jaenisch R. c-Myc is dispensable for direct reprogramming of mouse fibroblasts. Cell Stem Cell 2008; 2:10-12.

182 Nakagawa M, Koyanagi M, Tanabe K, et al. Generation of induced pluripotent stem cells without Myc from mouse and human fibroblasts. Nat Biotechnol 2008; 26:101-106.

183 Yamanaka S. Elite and stochastic models for induced pluripotent stem cell generation. Nature 2009; 460:49-52.

184 Mitsui K, Tokuzawa Y, Itoh H, et al. The homeoprotein Nanog is required for maintenance of pluripotency in mouse epiblast and ES cells. Cell 2003; 113:631-642.

185 Feng B, Jiang J, Kraus P, et al. Reprogramming of fibroblasts into induced pluripotent stem cells with orphan nuclear receptor Esrrb. Nat Cell Biol 2009; 11:197-203.

186 Yu J, Vodyanik MA, Smuga-Otto K, et al. Induced pluripotent stem cell lines derived from human somatic cells. Science 2007; 318:1917-1920.

187 Ghosh Z, Wilson KD, Wu Y, Hu S, Quertermous T, Wu JC. Persistent donor cell gene expression among human induced pluripotent stem cells contributes to differences with human embryonic stem cells. PLoS One 2010; 5:e8975.

188 Marchetto MC, Yeo GW, Kainohana O, Marsala M, Gage $\mathrm{FH}$, Muotri AR. Transcriptional signature and memory retention of human-induced pluripotent stem cells. PLoS One 2009; 4:e7076.

189 Carey BW, Markoulaki S, Hanna JH, et al. Reprogramming factor stoichiometry influences the epigenetic state and biological properties of induced pluripotent stem cells. Cell Stem Cell 2011; 9:588-598.

190 Newman AM, Cooper JB. Lab-specific gene expression signatures in pluripotent stem cells. Cell Stem Cell 2010; 7:258262.

191 Ward PS, Thompson CB. Metabolic reprogramming: a cancer hallmark even warburg did not anticipate. Cancer Cell 2012; 21:297-308.

192 Shyh-Chang N, Locasale JW, Lyssiotis CA, et al. Influence of threonine metabolism on S-adenosylmethionine and histone methylation. Science 2012 Nov 1. doi:0.1126/science. 1226603

193 Bultman S, Gebuhr T, Yee D, et al. A Brgl null mutation in the mouse reveals functional differences among mammalian SWI/SNF complexes. Mol Cell 2000; 6:1287-1295.

194 Kim JK, Huh SO, Choi H, et al. Srg3, a mouse homolog of yeast SWI3, is essential for early embryogenesis and involved in brain development. Mol Cell Biol 2001; 21:77877795.

195 Gaspar-Maia A, Alajem A, Meshorer E, Ramalho-Santos M. Open chromatin in pluripotency and reprogramming. Nat Rev Mol Cell Biol 2011; 12:36-47.

196 Peters AH, O'Carroll D, Scherthan H, et al. Loss of the Suv39h histone methyltransferases impairs mammalian heterochromatin and genome stability. Cell 2001; 107:323-337.

197 Tachibana M, Sugimoto K, Nozaki M, et al. G9a histone methyltransferase plays a dominant role in euchromatic histone $\mathrm{H} 3$ lysine 9 methylation and is essential for early embryogenesis. Genes Dev 2002; 16:1779-1791.

198 Dodge JE, Kang YK, Beppu H, Lei H, Li E. Histone H3-K9 methyltransferase ESET is essential for early development. Mol Cell Biol 2004; 24:2478-2486.

199 Welstead GG, Creyghton MP, Bilodeau S, et al. X-linked 
H3K27me3 demethylase Utx is required for embryonic development in a sex-specific manner. Proc Natl Acad Sci USA 2012; 109:13004-13009.

200 Fukuda T, Tokunaga A, Sakamoto R, Yoshida N. Fbx110/ $\mathrm{Kdm} 2 \mathrm{~b}$ deficiency accelerates neural progenitor cell death and leads to exencephaly. Mol Cell Neurosci 2011; 46:614624.

201 de Napoles M, Mermoud JE, Wakao R, et al. Polycomb group proteins Ring1A/B link ubiquitylation of histone $\mathrm{H} 2 \mathrm{~A}$ to heritable gene silencing and $\mathrm{X}$ inactivation. Dev Cell 2004; 7:663-676.

202 del Mar Lorente M, Marcos-Gutierrez C, Perez C, et al. Loss- and gain-of-function mutations show a polycomb group function for Ring1A in mice. Development 2000; 127:5093-5100.
203 van der Lugt NM, Domen J, Linders K, et al. Posterior transformation, neurological abnormalities, and severe hematopoietic defects in mice with a targeted deletion of the bmi-1 proto-oncogene. Genes Dev 1994; 8:757-769.

204 Chen T, Ueda Y, Dodge JE, Wang Z, Li E. Establishment and maintenance of genomic methylation patterns in mouse embryonic stem cells by Dnmt3a and Dnmt3b. Mol Cell Biol 2003; 23:5594-5605.

205 Wang ZQ, Auer B, Stingl L, et al. Mice lacking ADPRT and poly(ADP-ribosyl)ation develop normally but are susceptible to skin disease. Genes Dev 1995; 9:509-520.

206 Shi Y, Desponts C, Do JT, Hahm HS, Scholer HR, Ding S. Induction of pluripotent stem cells from mouse embryonic fibroblasts by Oct 4 and Klf4 with small-molecule compounds. Cell Stem Cell 2008; 3:568-574. 